\title{
Peripheral administration of a cell-penetrating MOTS-c analogue enhances memory and attenuates $A \beta 1-42$ or LPS induced memory impairment through inhibiting neuroinflammation
}

\author{
JinHong Jiang \\ Lanzhou University \\ Xin Chang \\ Lanzhou University \\ YaoYan Nie \\ Lanzhou University \\ YuXuan Shen \\ Lanzhou University \\ XueYa Liang \\ Lanzhou University \\ KangTai Xu \\ Lanzhou University \\ YaLi Peng \\ Lanzhou University \\ Min Chang ( $\square$ changmin@lzu.edu.cn ) \\ Lanzhou University
}

\section{Research}

Keywords: MOTS-c, AMPK, MAPK, neuroinflammation, astrocytes, microglia, dorsomorphin, LPS, Aß1-42, intranasal and intravenous

Posted Date: November 11th, 2019

DOI: https://doi.org/10.21203/rs.2.17059/v1

License: (c) (1) This work is licensed under a Creative Commons Attribution 4.0 International License.

Read Full License 


\section{Abstract}

Background: MOTS-c is a 16-amino acid mitochondrial derivative peptide reported to be involved in regulating insulin resistance and obesity, osteoporosis and inflammatory responses. Accumulating evidences suggest that inhibiting neuroinflammation is a potential target in therapeutic or preventive strategies for Alzheimer's disease (AD). Due to the widespread distribution of MOTS in the CNS and its role in metabolism and immune system, previous reports also pointed out that MOTS-c may be effective as a therapeutic option toward the prevention of the aging processes. Therefore, it is important to understand the roles of MOTS-c in neuroinflammation.

Methods: The mouse memory function was evaluated using novel object recognition (NOR) and object location recognition (OLR) tasks. Brain hippocampus tissue samples were analyzed by quantitative PCR, western blotting, ELISA and immunostaining. Near-infrared fluorescent and confocal microscopy experiments were used to detect the brain uptake and distribution of intranasal or intravenous MOTS-c or MP (MOTS-c conjugated with cell penetrating peptides). Peptides drugs were synthesized by a standard Fmoc-based solid-phase synthetic method.

Results: Central MOTS-c enhances object and location recognition memory formation and consolidation, and ameliorates the memory deficit induced by AB1-42 or LPS in NOR and OLR tasks, whereas dorsomorphin (AMPK inhibitor, i.p.) significantly blocked the memory-ameliorating effects of MOTS-c. Western blotting experiments showed that MOTS-c provided neuroprotection against LPS or AB1-42induced neuroinflammation, which was related with phosphorylation of AMPK, but not MAPK including ERK, JNK and p38. The underlying mechanism of MOTS-c neuroprotection may be involved of inhibiting the activation of astrocytes and microglia and production of proinflammatory cytokines including TNF-a, IL-6, IL-1 $\beta$, COX-2 and iNOS. In order to improve the brain intake of MOTS-C, we screen out (PRR) 5 , a cell penetrating peptides, as a carrier for MOTS-c into the brain. Then in NOR task, intranasal or intravenous MP, but not MOTS-c, showed good memory performance on memory formation, memory consolidation and memory impairment. Finally, compared with control and Rho-MOTS-c groups, significant fluorescence signals of Rho-MP were detected in the brain by NIR fluorescence imaging.

Conclusion: MOTS-c might be a new potential target for treatment of cognitive decline in AD and this way of administration MP will be the potential strategy for non-invasive therapeutic intervention.

\section{Background}

As the aging population increases, the number of patients with Alzheimer's disease (AD) grows steadily year by year. In $A D$, an accumulation of misfolded proteins such as amyloid- $\beta(A \beta)$ plaques and neurofibrillary tangles in brain evoke oxidative and inflammatory damage, which leads to progressive cognitive dysfunction, memory impairment and behavioral changes[1-3]. Increasing evidences suggest that dysfunctional mitochondria release oxidative free radicals, which cause considerable oxidative 
stress in $A D[4,5]$. Currently, mitochondria appear may mediate, drive, or even initiate pathologic molecular cascades in $A D$, which represents a reasonable therapeutic target $[6,7]$.

In addition, mounting evidences have demonstrated the roles of neuroinflammation in the pathogenesis of $A D$ [8-11]. On one hand, microglia, the first line of defense and the resident macrophages of the brain in the central nervous system (CNS), play multiple roles in AD pathogenesis by releasing proinflammatory mediators to accelerate $A \beta$ production and accumulation[11, 12]. On the other hand, astrocytes, the most abundant type of glial cells in the CNS, release anti-inflammatory cytokines to degrade the increasing amounts of toxic $A \beta$ plaques. $A \beta$ accumulation, the activation of microglia and astrocytes and inflammatory mediators further strengthen the neuroinflammatory response in the brain, which will in turn lead to a vicious circle[13-15]. Targeting of these immune mechanisms could lead to future therapeutic or preventive strategies for AD.

MOTS-c is a recently discovered derivative peptide encoded by the open reading frame (sORF) in mitochondrial 12S rRNA. The sequence of MOTS-c is MRWQEMGYIFYPRKLR, and the N-terminally 11 residues of which is very conserved in many species[16]. Meanwhile, it is widely distributed in CNS and peripheral tissues[16, 17]. Although the target of MOTS-c has not yet been identified, previous reports have shown its role in regulating metabolic homeostasis, obesity and insulin resistance, and osteoporosis[16-19]. Notably, MOTS-c has a significant inhibitory effect on the expression of inflammation and immune-related genes[20-22]. Meanwhile, Cohen et al pointed out that MOTS-c may be effective as a therapeutic option toward the prevention of the aging processes[16].

In this study, therefore, we assessed the roles of MOTS-c in cognition and $A \beta_{1-42}$ and LPS induced AD mice model by using object location recognition (OLR) and novel object recognition (NOR) tasks. It is a non-aversive learning paradigm relied on spontaneous exploratory behavior of animal.

Last but not least, it is worth noting that in the clinical treatment study of $A D$, the ability of a series of macromolecular inhibitors including proteins and peptides to enter the brain has been an important indicator of therapeutic efficacy[23-25]. Meanwhile, our experiments show that peripheral administration of MOTS-c does not cross the blood-brain barrier (BBB) and plays an invalid effect. In order to improve the brain intake of MOTS-c, we designed and synthesized a series of brain-targeted cell penetrating peptides to screen out suitable carriers for MOTS-c into the brain.

\section{Methods}

\subsection{Animals}

Male Kunming mice (a swiss strain, weighing 20-22 g, 8-10 weeks-old) were obtained from the Experimental Animal Center of Lanzhou University. All the protocols in this study were approved by the Ethics Committee of Lanzhou University (approval number, SYXK Gan 2009-0005). Each mouse was housed in $20 \times 30 \mathrm{~cm}^{2}$ cages (bedding-wood shavings, humidity $45-50 \%, 5$ animals/cage) with free 
access to tap water and food in an animal room, which was maintained at $22 \pm 2{ }^{\circ} \mathrm{C}$ and accompanied by a $12 \mathrm{~h}$ light-dark cycle (8 a.m.-8 p.m.).

\subsection{Surgery}

A 8-mm 26-gauge stainless-steel guide cannula was implanted into the lateral ventricle or bilateral hippocampus CA1 according to our previous report[26]. All mice (20-22 g) were anesthetized with sodium pentobarbital at a dose of $70 \mathrm{mg} / \mathrm{kg}$ (Sigma-Aldrich, Merck KGaA) and fixed in a stereotaxic frame (Leica, Germany). According to the atlas of Paxinos and Franklin[27], guide cannula was implanted over the lateral ventricle (i.c.v., $\mathrm{AP}=0.5 \mathrm{~mm}, \mathrm{RL}=1.0 \mathrm{~mm}, \mathrm{DV}=2.0 \mathrm{~mm}$ ), or was implanted into the bilateral hippocampus CA1 (iCA1, AP = $2 \mathrm{~mm}, \mathrm{RL}= \pm 1.5 \mathrm{~mm}, \mathrm{DV}=1.2 \mathrm{~mm}$ ). After surgery, each mouse was individually raised and allowed to recover 5-7 days. All experiments were conducted between 9 a.m. and 6 p.m.

\subsection{Drugs}

MOTS-C, MP and a series of cell penetrating peptides (CPPs) were synthesized by a standard Fmocbased solid phase synthesis method, and the obtained crude peptide was purified to homogeneity by preparative HPLC. The purity of the peptide was determined by analytical HPLC and ESI-TOF MS. Detailed data is displayed in supplemental materials (Fig S1-S13). $A \beta_{1-42}$ peptide was purchased from Hangzhou Chinese Peptide Biochemical Company. $A \beta_{1-42}$ was first dissolved in hexafluoroisopropanol and freezed at $-80^{\circ} \mathrm{C}$, and it was directly lyophilized to form an $A \beta_{1-42}$ oligomer. Then it was dissolved in $5 \%$ DMSO in saline, kept at $-20^{\circ} \mathrm{C}$, and was diluted in saline immediately before injection ( $\left.800 \mathrm{pmol} / \mathrm{mouse}\right)$. LPS was bought from Sigma (Sigma-Aldrich, Merck KGaA) and was dissolved in saline $(1 \mu \mathrm{g} / \mu \mathrm{l})$. Dorsomorphin was purchased from Sigma and was dissolved in $5 \% \mathrm{DMSO}$ in saline, kept at $-20^{\circ} \mathrm{C}$, and was diluted in saline immediately before intraperitoneal injection $(25 \mathrm{mg} / \mathrm{kg})$.

\subsection{Treatment}

Different doses of drugs were infused into brain by using a 32-gauge stainless steel syringe needle placed in and projecting $0.5 \mathrm{~mm}$ below the tip of the cannula for $2 \mathrm{~min}$. This needle was connected via a PE tube to a $5 \mu \mathrm{l}$ Hamilton syringe mounted on a Microdrive pump (KD Scientific). This needle remained in place for $1 \mathrm{~min}$ after drug infusion to allow for drug diffusion. For the lateral ventricle, injection volume is $2 \mu \mathrm{l}$, and for the bilateral hippocampus CA1, injection volume is $0.5 \mu \mathrm{l} /$ side. The behavior experiments were carried out 15 minutes after i.c.v. injection of MOTS-c. In addition, for nasal application, mice were anesthetized with isoflurane and infused with MOTS-c $(25 \mu \mathrm{g}, 10 \mu \mathrm{l})$ using a $10 \mu \mathrm{l}$ pipette. MOTS-c was dissolved in $10 \% \beta$-cyclodextrin for nasal application. Each application of the left and right rhinarium lasts for 1 minute, respectively. Two hours after intranasal administration, the mice were returned to their home cages and subjected to behavioral experiments. In order to minimize non-specific stress responses during the injection of the drug, the mice were handled daily for 2-3 minutes before the start of the experiment. The selection of dose was based on previous reports and our preliminary observations[26]. 
At the end of the experiment, the correct position of the cannula was examined by injecting methylene blue into the cannula. After the behavioral study, each mouse was sacrificed by cervical dislocation and the brain was immediately dissected, and the position of each cannula was determined. Data showing the diffusion of methylene blue in the ventricles were analyzed in statistical evaluation. In addition, the bilateral hippocampus CA1 position was checked by haematoxylin eosin (H\&E) staining, which were described in detail in our previous reports $[26,28]$. All mice were used only once.

\subsection{Behavioral tasks}

The procedures for the novel object recognition (NOR) and object location recognition (OLR) tasks were described in detail in our previous report[26,28]. The procedure of NOR and OLR tasks consisted of two sessions: the training phase, the test phase and the time elapsed between the training and test phases ( 1 day or 3 days). Prior to training, each mouse was handled for 3 min per day for three consecutive days. Each mouse was trained and tested in its home cage in a sound-attenuated room with dim lighting. In our experiments, all objects were made of plastic or glass and were similar in sizes (4-5 $\mathrm{cm}$ high) but different in color and shape. Each object has multiple copies and can be used interchangeably. Thoroughly clean the object between experiments to avoid olfactory cues. Exploration was defined as sniffing or touching objects with the nose and/or forepaws. Sitting or moving around an object was not considered an exploratory behavior. The time spent exploring each object was recorded by an observer blind to the treatment. In addition, there was no significant difference in the duration of the training phase, as well as in the duration and the total exploration time (TET) of the test phase (Table 1).

Table 1. Duration of training phase and test phase and TET in test phase for each group. 


\begin{tabular}{|c|c|c|c|c|c|}
\hline Figure & Group & $\begin{array}{c}\text { Duration of training } \\
\text { phase }(\mathrm{s})\end{array}$ & $\begin{array}{l}\text { Duration of test } \\
\text { phase (s) }\end{array}$ & $\begin{array}{l}\text { TET in test } \\
\text { phase(s) }\end{array}$ & $\mathrm{n}$ \\
\hline \multirow[t]{2}{*}{ Fig.1A } & Control & $140.8 \pm 26.4$ & $249.2 \pm 16.9$ & $23.8 \pm 0.6$ & 11 \\
\hline & MOTS-c & $125.8 \pm 29.5$ & $250.0 \pm 38.7$ & $19.1 \pm 4.0$ & 9 \\
\hline \multirow[t]{2}{*}{ Fig.1B } & Control & $138.2 \pm 23.2$ & $298.4 \pm 1.7$ & $18.5 \pm 1.5$ & 10 \\
\hline & $\begin{array}{l}\text { MOTS-c } \\
\text { Control }\end{array}$ & $\begin{array}{l}100.9 \pm 19.4 \\
979+196\end{array}$ & $\begin{array}{l}194.9 \pm 35.6 \\
236+265\end{array}$ & $22.7 \pm 1.4$ & 8 \\
\hline Fig.1C & $\begin{array}{l}\text { Control } \\
\text { MOTS-c }\end{array}$ & $\begin{array}{l}97.9 \pm 19.6 \\
126.6 \pm 37.4\end{array}$ & $\begin{array}{l}236 \pm 26.5 \\
255.4+256\end{array}$ & $\begin{array}{l}21.5 \pm 2.1 \\
186+28\end{array}$ & 9 \\
\hline \multirow[t]{2}{*}{ Fig.1D } & Control & $184.4 \pm 38.6$ & $194.6 \pm 35.7$ & $22.6 \pm 1.4$ & 7 \\
\hline & MOTS-c & $175.1 \pm 26.7$ & $251.9 \pm 37.6$ & $17.2 \pm 3.2$ & 8 \\
\hline Fig.1E & $\begin{array}{l}\text { Control } \\
\text { MOTS-c }\end{array}$ & $\begin{array}{l}139.7 \pm 23.3 \\
91.2 \pm 14.8\end{array}$ & $\begin{array}{l}257.1 \pm 36.6 \\
231.3 \pm 27.5\end{array}$ & $\begin{array}{l}21.2 \pm 2.8 \\
19.9 \pm 0.8\end{array}$ & $\begin{array}{l}8 \\
8\end{array}$ \\
\hline \multirow[t]{2}{*}{ Fig.1F } & Control & $111 \pm 21.3$ & $269.2 \pm 24.3$ & $22.2 \pm 1.1$ & 8 \\
\hline & MOTS-c & $129.4 \pm 26.7$ & $234.2 \pm 36.1$ & $16.6 \pm 2.4$ & 7 \\
\hline \multirow[t]{2}{*}{ Fig.2A } & Control & $137.5 \pm 25.1$ & $229.6 \pm 23.5$ & $19.9 \pm 2.5$ & 6 \\
\hline & MOTS-c & $\begin{array}{l}216.5 \pm 25.4 \\
983+145\end{array}$ & $274.8 \pm 23.5$ & $17.0 \pm 2.0$ & 10 \\
\hline Fig.2B & $\begin{array}{l}\text { Control } \\
\text { MOTS-c }\end{array}$ & $\begin{array}{l}98.3 \pm 14.5 \\
96.1 \pm 12.9\end{array}$ & $\begin{array}{l}210.2 \pm 26.7 \\
276.4 \pm 14.9\end{array}$ & $\begin{array}{l}24.2 \pm 0.8 \\
21.4 \pm 1.6\end{array}$ & $\begin{array}{l}9 \\
8\end{array}$ \\
\hline \multirow{2}{*}{ Fig.2C } & Control & $143.0 \pm 27.2$ & $216.6 \pm 25.1$ & $24.6 \pm 0.5$ & 8 \\
\hline & MOTS-c & $149.5 \pm 16.9$ & $300 \pm 0$ & $16.9 \pm 1.8$ & 9 \\
\hline \multirow[t]{2}{*}{ Fig.2D } & Control & $176.0 \pm 23.8$ & $231.6 \pm 30.2$ & $20.6 \pm 2.1$ & 7 \\
\hline & MOTS-c & $154.8 \pm 20.1$ & $210.4 \pm 28.9$ & $24.4 \pm 0.6$ & 7 \\
\hline Fig.2E & $\begin{array}{l}\text { Control } \\
\text { MOTS-c }\end{array}$ & $\begin{array}{l}104.7 \pm 22.6 \\
188.5 \pm 29.8\end{array}$ & $\begin{array}{l}230.8 \pm 31.5 \\
252.5 \pm 25.8\end{array}$ & $\begin{array}{l}21.7 \pm 1.8 \\
18.7 \pm 2.6\end{array}$ & $\begin{array}{l}6 \\
7\end{array}$ \\
\hline \multirow[t]{2}{*}{ Fig.2F } & Control & $151.0 \pm 27.9$ & $253.1 \pm 24.7$ & $19.7 \pm 2.7$ & 7 \\
\hline & MOTS-c & $137.8 \pm 22.0$ & $245.2 \pm 20.3$ & $23.9 \pm 0.7$ & 9 \\
\hline \multirow[t]{3}{*}{ Fig.3A } & Control & $117.1 \pm 18.1$ & $230 \pm 30.4$ & $19.1 \pm 3.7$ & 7 \\
\hline & $\begin{array}{c}\mathrm{A} \beta \\
\mathrm{A} \beta+\mathrm{MOTS}-\mathrm{C}\end{array}$ & $\begin{array}{l}136.0 \pm 23.6 \\
90.2 \pm 19.4\end{array}$ & $\begin{array}{l}298.2 \pm 1.1 \\
170.6 \pm 35.7\end{array}$ & $\begin{array}{l}18.5 \pm 1.5 \\
20.1 \pm 1.4\end{array}$ & $\begin{array}{l}7 \\
7\end{array}$ \\
\hline & $A \beta+$ Dorsomorphin+MOTS-C & $131.1 \pm 14.2$ & $300 \pm 0$ & $19.3 \pm 1.1$ & 8 \\
\hline \multirow[t]{2}{*}{ Fig.3B } & $\begin{array}{c}\text { Control } \\
A \beta\end{array}$ & $\begin{array}{c}91.2 \pm 14.2 \\
129.4 \pm 26.7\end{array}$ & $\begin{array}{l}279.1 \pm 24.3 \\
229.6 \pm 23.5\end{array}$ & $\begin{array}{l}22.2 \pm 1.2 \\
20.1 \pm 2.5\end{array}$ & $\begin{array}{l}8 \\
9\end{array}$ \\
\hline & $\begin{array}{c}\text { A } \beta+\text { MOTS-C } \\
A \beta+\text { orsomorphin+MOTS-c }\end{array}$ & $\begin{array}{c}199.2 \pm 117.2 \\
151.0 \pm 15.6\end{array}$ & $\begin{array}{l}280.5 \pm 15.9 \\
300 \pm 0\end{array}$ & $\begin{array}{l}20.7 \pm 1.6 \\
17.9 \pm 1.2\end{array}$ & $\begin{array}{l}8 \\
8\end{array}$ \\
\hline Fig.3C & $\begin{array}{l}\text { Control } \\
\text { LPS }(1 \mu \mathrm{g}) \\
\text { LPS }(2 \mu \mathrm{g}) \\
\text { LPS }(4 \mu \mathrm{g})\end{array}$ & $\begin{array}{c}226.3 \pm 20.7 \\
230 \pm 23.9 \\
300 \pm 0 \\
192.7 \pm 29.6\end{array}$ & $\begin{array}{c}300 \pm 0 \\
300 \pm 0 \\
271.3 \pm 24.8 \\
247.3 \pm 27.4\end{array}$ & $\begin{array}{l}16.9 \pm 1.7 \\
12.6 \pm 1.2 \\
16.6 \pm 2.2 \\
19.7 \pm 1.9\end{array}$ & $\begin{array}{l}11 \\
9 \\
7 \\
9\end{array}$ \\
\hline \multirow[t]{3}{*}{ Fig.3D } & Control & $210.3 \pm 22.1$ & $300 \pm 0$ & $19.5 \pm 1.7$ & 10 \\
\hline & $\begin{array}{c}\text { LPS } \\
\text { LPS+MOTS-c }\end{array}$ & $\begin{array}{l}222.3 \pm 30.4 \\
263.8 \pm 19.6\end{array}$ & $\begin{array}{l}300 \pm 0 \\
300 \pm 0\end{array}$ & $\begin{array}{l}15.8 \pm 0.7 \\
14.4 \pm 1.1\end{array}$ & $\begin{array}{l}8 \\
7\end{array}$ \\
\hline & $\underset{C}{\text { LPS+Dorsomorphin+MOTS- }}$ & $143.6 \pm 19.0$ & $245.1 \pm 19.2$ & $21.0 \pm 1.0$ & 7 \\
\hline \multirow[t]{3}{*}{ Fig.3E } & Control & $194.2 \pm 28.7$ & $300 \pm 0$ & $15.4 \pm 1.6$ & 8 \\
\hline & $\begin{array}{c}\text { LPS } \\
\text { LPS+MOTS-c }\end{array}$ & $\begin{array}{l}214.0 \pm 26.5 \\
191.8 \pm 25.8\end{array}$ & $\begin{array}{l}300 \pm 0 \\
300 \pm 0\end{array}$ & $\begin{array}{l}17.9 \pm 1.0 \\
15.3 \pm 1.3\end{array}$ & $\begin{array}{l}8 \\
8\end{array}$ \\
\hline & $\underset{c}{\text { LPS+Dorsomorphin+MOTS- }}$ & $171.9 \pm 11.3$ & $275.9 \pm 32.1$ & $19.8 \pm 2.1$ & 9 \\
\hline \multirow[t]{2}{*}{ Fig.8A } & Control & $163.1 \pm 13.6$ & $261.5 \pm 15.6$ & $\begin{array}{l}17.1 \pm 1.0 \\
150 \pm 12\end{array}$ & $\begin{array}{l}8 \\
8\end{array}$ \\
\hline & $\begin{array}{l}\text { i.n. MOTS-c } \\
\text { i.n. MOTS }\end{array}$ & $\begin{array}{l}198.2 \pm 25.1 \\
178.3 \pm 21.3\end{array}$ & $286.7 \pm 21.8$ & $\begin{array}{l}15.9 \pm 1.3 \\
16.3 \pm 1.7\end{array}$ & $\begin{array}{l}8 \\
9\end{array}$ \\
\hline \multirow[t]{3}{*}{ Fig.8B } & Control & $175.9 \pm 31.2$ & $256.1 \pm 18.3$ & $16.0 \pm 1.1$ & 7 \\
\hline & ICV MOTS-C & $166.1 \pm 21.4$ & $300 \pm 0$ & $17.0 \pm 1.9$ & 8 \\
\hline & i.n. MOTS-c & $155.3 \pm 18.9$ & $300 \pm 0$ & $17.5 \pm 1.3$ & 9 \\
\hline \multirow[t]{4}{*}{ Fig.8C } & Control & $189.8 \pm 11.3$ & $291.3 \pm 31.6$ & $13.7 \pm 1.0$ & 8 \\
\hline & LPS & $145.3 \pm 12.3$ & $300 \pm 0$ & $16.6 \pm 0.9$ & 8 \\
\hline & LPS+ICV MOTS-C & $189.6 \pm 33.6$ & $300 \pm 0$ & $15.3 \pm 1.3$ & 9 \\
\hline & LPS+i.n. MOTS-c & $163.1 \pm 25.1$ & $300 \pm 0$ & $17.1 \pm 1.1$ & 7 \\
\hline \multirow[t]{2}{*}{ Fig.10A } & Control & $198.3 \pm 29.9$ & $260.5 \pm 26.03$ & $19.6 \pm 1.9$ & 9 \\
\hline & ICV MOTS-C & $230.8 \pm 28.2$ & $300 \pm 0$ & $18.2 \pm 1.8$ & 8 \\
\hline
\end{tabular}




\begin{tabular}{|c|c|c|c|c|c|}
\hline \multirow[b]{5}{*}{ Fig.10B } & IN MP & $268.3 \pm 19.6$ & $300 \pm 0$ & $15.4 \pm 0.6$ & 7 \\
\hline & IN MOTS-c & $211.9 \pm 29.4$ & $300 \pm 0$ & $13.6 \pm 1.0$ & 9 \\
\hline & IV MP & $169.1 \pm 21.9$ & $300 \pm 0$ & $19.0 \pm 1.7$ & 8 \\
\hline & IV MOTS-c & $249.3 \pm 18.9$ & $300 \pm 0$ & $16.2 \pm 1.7$ & 9 \\
\hline & Control & $213.1 \pm 31.0$ & $291.2 \pm 9.3$ & $17.8 \pm 1.8$ & 7 \\
\hline & ICV MOTS-c & $199.3 \pm 31.3$ & $287.0 \pm 14.5$ & $17.8 \pm 1.4$ & 8 \\
\hline & IN MP & $292.5 \pm 6.5$ & $300 \pm 0$ & $14.9 \pm 1.3$ & 6 \\
\hline & IN MOTS-c & $237.0 \pm 23.7$ & $300 \pm 0$ & $14.7 \pm 1.6$ & 8 \\
\hline & IV MP & $239.6 \pm 21.3$ & $300 \pm 0$ & $18.1 \pm 1.0$ & 7 \\
\hline & IV MOTS-c & $254.1 \pm 17.6$ & $300 \pm 0$ & $21.3 \pm 1.3$ & 9 \\
\hline \multirow[t]{7}{*}{ Fig.10C } & Control & $265.6 \pm 32.2$ & $300 \pm 0$ & $17.7 \pm 0.9$ & 8 \\
\hline & LPS & $204.7 \pm 31.6$ & $300 \pm 0$ & $17.1 \pm 1.4$ & 9 \\
\hline & LPS+ICV MOTS-c & $244.1 \pm 31.1$ & $255.1 \pm 29.9$ & $19.8 \pm 1.8$ & 8 \\
\hline & LPS+IN MP & $258.3 \pm 24.4$ & $265.1 \pm 22.7$ & $19.6 \pm 1.9$ & 7 \\
\hline & LPS+IN MOTS-c & $244.9 \pm 24.7$ & $300 \pm 0$ & $13.9 \pm 0.8$ & 7 \\
\hline & LPS+IV MP & $231.1 \pm 35.2$ & $300 \pm 0$ & $17.3 \pm 1.2$ & 8 \\
\hline & LPS+IV MOTS-c & $243.6 \pm 29.0$ & $300 \pm 0$ & $19.2 \pm 1.6$ & 8 \\
\hline
\end{tabular}

Note: Data are presented as mean \pm SEM. There was no significant difference between groups $(p>0.05$ for each comparison)

\subsubsection{NOR task}

In the training phase, two identical objects were placed on opposite sides of the home cage. The training trial was ended when the mouse had explored the two identical objects for $5 \mathrm{~s}$ or $10 \mathrm{~s}$ within 5 min. Animal were eliminated if TET in the training phase did not reach $5 \mathrm{~s}$ within 3 min or $10 \mathrm{~s}$ within 5 min. In the test phase, a novel object and a familiar object from the training trial were placed in the same positions as in the training phase, and the test phase lasted for $5 \mathrm{~min}$. The test phase was ended when the mouse had explored the two objects for a total of $25 \mathrm{~s}$, or after $5 \mathrm{~min}$ had passed, the test phase was terminated. The discrimination index (DI) in the test phase was calculated as a percentage of the time spent exploring the novel object over the total time spent exploring both objects. A DI of $50 \%$ is equivalent to the chance level, indicating that mice failed to make a distinction between the novel object and the familiar one. A significantly higher DI indicates that mice had a preference for novel object, indicating that they could remember the familiar object.

\subsubsection{OLR task}

In the training phase, two selfsame objects were placed in distinct corners of the home cage. The training trial was ended when the mouse had explored the two identical objects for $5 \mathrm{~s}$ or $10 \mathrm{~s}$ within 5 min. Animal were eliminated if the TET in the training phase could not reach $5 \mathrm{~s}$ within 3 min or $10 \mathrm{~s}$ within $5 \mathrm{~min}$. In the test phase, one of the objects was moved to a new corner, which was randomly chosen, and the test phase lasted for $5 \mathrm{~min}$. The test phase was ended when mouse had explored two locations of the objects for a total of $25 \mathrm{~s}$, or after $5 \mathrm{~min}$ had passed, the test phase was terminated. The $\mathrm{DI}$ in the test phase was calculated as a percentage of the time spent exploring the new location over the total time spent exploring both locations. A DI of $50 \%$ is equivalent to the chance level, indicating that mice failed to make a distinction between the novel location and the familiar one. A significantly higher 
DI indicates that mice had a preference for new location, indicating that they could remember the familiar location.

\subsection{Cell Culture}

BV-2 and U87 cells were obtained from cellbank.org.cn. BV-2 and U87 cells were cultured in DMEM containing $10 \%$ fetal bovine serum at $37{ }^{\circ} \mathrm{C}$ in a humidified $5 \% \mathrm{CO}_{2}$ incubator. $\mathrm{BV}-2$ and U87 cells were pretreated with CPPs $(5 \mu \mathrm{mol})$ for $2 \mathrm{~h}$ and then subjected to laser confocal experiment, flow cytometry and MTT assay in vitro.

\subsection{Western blotting (WB)}

Western blotting was carried out as manufacturer's instructions (Bio-Rad Laboratories, Inc). Protein was extracted with RIPA buffer containing protease inhibitor (Thermo Fisher Scientific, Inc.). The protein concentration was determined using a BCA protein assay kit (Thermo Fisher Scientific, Inc.). Briefly, the protein samples ( $40 \mu \mathrm{g}$ per lane) isolated from the hippocampus were separated by SDS-PAGE and electrophoretically transferred onto polyvinylidene fluoride (PVDF) membranes. Membranes were blocked with $5 \%$ fat-free milk for $2 \mathrm{~h}$ and incubated overnight at $4{ }^{\circ} \mathrm{C}$ with specific first antibodies. GAPDH was used as a loading control. The first antibodies in WB assay were shown in Table 2. Subsequently, after being washed three times with PBS, the membranes were incubated with the corresponding secondary antibodies. The reaction was visualized with chemiluminescence reagents provided with an ECL kit (Thermo Fisher Scientific, Inc.) and exposed to a film. The intensity of the blots was quantified with densitometry (Image J 1.49v; National Institutes of Health).

Table 2. Antibody information used in this experiment.

\begin{tabular}{cccc}
\hline Antibody Name & Dilution Concentration & Cat Number & Company \\
\hline Anti-p-AMPK Rabbit mAb & $1: 1000$ & $5831 S$ & CST, USA \\
Anti-t-AMPK Rabbit mAb & $1: 1000$ & $2535 S$ & CST, USA \\
Anti-p-p38 Rabbit mAb & $1: 1000$ & 45115 & CST, USA \\
Anti-t-p38 Rabbit mAb & $1: 1000$ & $9212 S$ & CST, USA \\
Anti-p-ERK Rabbit mAb & $1: 1000$ & $4370 T$ & CST, USA \\
Anti-t-ERK Rabbit mAb & $1: 500$ & AM076-1 & Beyotime \\
Anti-p-JNK Rabbit mAb & $1: 1000$ & A688T & CST, USA \\
& & & \\
Anti-t-JNK Rabbit mAb & $1: 500$ & AJ518-1 & Beyotime \\
GAPDH Rabbit mAb & $1: 1000$ & $5174 S$ & CST, USA \\
Second antibody & $1: 1000$ & A0208 & Beyotime \\
\hline
\end{tabular}

\subsection{Real time quantitative polymerase chain reaction (RT-qPCR) analysis}

RT-qPCR was performed according to the manufacturer's protocol (Takara Bio, Inc). Total RNA was extracted from hippocampus by Trizol ${ }^{\circledR}$ reagent (Thermo Fisher Scientific, Inc.). Following the manufacturer's instructions, then $1 \mu \mathrm{g}$ RNA in each sample was reversely transcribed into cDNA with the 5X PrimeScript RT Master Mix (Takara Bio, Inc.), the following conditions: $37^{\circ} \mathrm{C}$ for $15 \mathrm{~min}, 85^{\circ} \mathrm{C}$ for $5 \mathrm{sec}$, 
$4^{\circ} \mathrm{C}$ for $3 \mathrm{~min}$. Amplification was carried out in a $25 \mu \mathrm{L}$ reaction mixture consisting of $12.5 \mu \mathrm{L} 2 \mathrm{X}$ SYBR Premis Ex TaqTM II (Takara Bio, Inc.), $2 \mu \mathrm{L}$ cDNA, $1 \mu \mathrm{L}$ forward primer, $1 \mu \mathrm{L}$ reverse primer and $8.5 \mu \mathrm{L} \mathrm{H}_{2} \mathrm{O}$, and was run under the following conditions: $95^{\circ} \mathrm{C}$ for $30 \mathrm{sec}$, followed by 40 cycles at $95^{\circ} \mathrm{C}$ for $5 \mathrm{sec}, 58^{\circ} \mathrm{C}$ for $30 \mathrm{sec}$ and $72^{\circ} \mathrm{C}$ for $30 \mathrm{sec}$. The primers are presented in Table 3 and GAPDH was used as the reference gene. The primers are used in the RT-qPCR assay to identify the expression level of TNF-a, IL-6, IL- $1 \beta$ and iNOS gene in control, $A \beta$ and $A \beta+$ MOTS-c, or control, LPS and LPS+MOTS-c groups.

Table 3. Primers information used in this experiment.

\begin{tabular}{|c|c|c|}
\hline Gene & Prime & Sequence $\llbracket 5^{\prime}-3^{\prime} \square$ \\
\hline IL-1 $\beta$ & $\begin{array}{c}\text { sense } \\
\text { anti-sense }\end{array}$ & CAGCTTCAAATCTCGCAGCA \\
\hline TNF-a & $\begin{array}{l}\text { sense } \\
\text { anti-sense }\end{array}$ & $\begin{array}{l}\text { ACTCCCAGGTTCTCTTCAAGG } \\
\text { GGCAGAGAGGAGGTTGACTTTC }\end{array}$ \\
\hline iNOS & sense & CGCAGCTGGGCTGTACAAAC \\
\hline IL-6 & $\begin{array}{l}\text { anti-sense } \\
\text { sense }\end{array}$ & ACAACCACGGCCTTCCCTA \\
\hline COX-2 & $\begin{array}{l}\text { anti-sense } \\
\text { sense }\end{array}$ & $\begin{array}{l}\text { TCATTTCCACGATTTCCCAGA } \\
\text { GGGAAGAAATGTGCCAATTGC }\end{array}$ \\
\hline & $\begin{array}{l}\text { anti-sense } \\
\text { sense } \\
\text { anti-sense }\end{array}$ & $\begin{array}{l}\text { GGGAGAAGCGTTTGCGGTACT } \\
\text { GCCACAGACGTCACTTTCCTAC } \\
\text { CGGGAACACAGTCACATACCA }\end{array}$ \\
\hline
\end{tabular}

IL-1 $\beta$, interleukin-1 $\beta$; TNF- $a$, tumor necrosis factor-a; iNOS, nitric oxide synthase; IL-6, interleukin-6; COX-2, cyclooxygenase-2.

\subsection{Enzyme-Linked Immunoassay (ELISA)}

Total proteins from the hippocampus were extracted with RIPA lysis buffer containing protease inhibitor (Thermo Fisher Scientific, Inc.). Total proteins were determined using a bicinchoninic acid protein assay kit (Sangon Biotech Co., Ltd.). According to the manufacturer's protocol, IL-1 $\beta$, IL-6 and TNF- $\alpha$ in the hippocampus tissue were measured using ELISA kits (Elabscience, Wuhan).

\subsection{Immunostaining}

Mice were anesthetized with sodium pentobarbital, then transcardially perfused with $20 \mathrm{ml}$ PBS followed by $60 \mathrm{ml} 4 \%$ paraformaldehyde. The brains were removed and cut into consecutive frozen sections and then incubated overnight with CD11b antibody (cat number: GB11058, 1:100, Servicebio, Wuhan) and anti-glial fibrillary acidic protein (GFAP) (cat number: GB11096, 1:100, Servicebio, Wuhan). The secondary antibody (cat number: A0521, Cy3-labeled Goat Anti-Mouse lgG, 1:200, Beyotime or cat number: A0562, FITC-labeled Goat Anti-Rabbit IgG, 1:200, Beyotime) was applied to the sections for 120 min at room temperature. The images were performed by a fluorescent microscope (ZEISS International, optical and optoelectronic technology, Germany).

\subsection{Confocal microscopy}


To confirm the penetration of MOTS-c or a series of CPPs in cells, the fluorescent dye (fluorescein isothiocyanate, FITC) was used. We labeled the N-terminus of MOTS-C or CPPs with FITC and the specific synthetic method was shown in the supplemental material. Firstly, BV-2 and U87 cells $\left(1 \times 10^{5}\right.$ cells/well) were plated into 12 well microplates and cultured overnight. $5 \mu \mathrm{M}$ FITC-labeled peptides were added to 12 well microplates with serum-free medium and returned to the carbon dioxide incubator for $12 \mathrm{~h}$.

Subsequently, the cells were washed twice with PBS. The peptide bound to the cell membrane needs to be removed by $0.02 \%$ trypsinization. Then, the cell was washed twice with PBS. Finally, the 12 -well plate was placed on a laser confocal microscope and photographed.

To confirm the penetration of MOTS-c or MP in the brain tissue of mice, we labeled the N-terminus of MOTS-c or MP with the fluorescent dye (Rhodamine B, Rho) and the specific synthetic method was shown in the supplemental material. Two hours after intranasal administration of Rho-MOTS-c or RhoMP alone into nasal cavity, mice were sacrificed and perfused with $20 \mathrm{ml}$ PBS to remove residual blood followed by $60 \mathrm{ml} 4 \%$ paraformaldehyde. The frozen brain tissue was cut into $30 \mu \mathrm{m}$-thick sections using a cryotome and observed with an Olympus FluoView FV1000 confocal laser scanning microscope [29].

\subsection{Flow cytometry}

To obtain a direct insight into the cellular uptake of FITC-labeled peptides in cells, BV-2 and U87 cells (1 $\times 10^{6}$ cells/well) were plated into 6 well microplates and cultured overnight. $5 \mu \mathrm{M}$ FITC-labeled peptides were added to 6 well microplates with serum-free medium and returned to the carbon dioxide incubator for $12 \mathrm{~h}$. Subsequently, the cells were washed twice with PBS. The peptide bound to the cell membrane needs to be removed by $0.02 \%$ trypsinization. The cells were harvested and centrifuged at 1,000 rpm for 5 min. Then, the cell pellet was washed twice with PBS and repeatedly blown down and resuspended in PBS. Finally, fluorescence intensity of $1 \times 10^{6}$ cells was analyzed with an FACS caliber flow cytometer using 488-nm laser excitation.

\subsection{MTT Assay}

To confirm the cytotoxicity of CPPs in BV-2 and U87 cells, MTT Assay was used. BV-2 and U87 cells (1 $\times 10^{4}$ cells/well) were plated into 96 well microplates and cultured overnight. Different concentrations of $(P R R)_{5}$ and Antp (pAntp(43-58), later named penetratin) were added to 96 well microplates with serumfree medium and returned to the carbon dioxide incubator for $12 \mathrm{~h} .10 \mu \mathrm{MTT}(5 \mathrm{mg} / \mathrm{mL})$ was added to 96 well microplates and incubated for 4 hours at $37^{\circ} \mathrm{C}$. Then, the medium was removed, and $150 \mu \mathrm{l}$ of dimethyl sulfoxide (DMSO) was added to each well while repeatedly shaking and mixing to completely dissolve. The absorbance was measured at $490 \mathrm{~nm}$ using a microplate reader.

Cell viability (\%) was calculated using the following formula:

$\left(O D^{\text {Drug }}-O D^{\text {Blank }}\right) /\left(O D^{\text {Control }}-O D^{\text {Blank }}\right) * 100 \%$ 


\subsection{NIR fluorescence imaging}

NIR fluorescence imaging was performed by a whole-mouse imaging system (Imaging Station IVIS Lumina II, Caliper). To confirm the penetration of MOTS-c or MP in the brain tissue of mice, the fluorescent dye (Rhodamine B, Rho) was used. We labeled the N-terminus of MOTS-c or MP with Rho and the specific synthetic method was shown in the supplemental material. Two hours after intranasal administration of Rho-MOTS-c or Rho-MP alone into nasal cavity, mice were sacrificed and perfused with $20 \mathrm{ml}$ PBS to remove residual blood in the brain. The brain was removed and placed into an imaging system. Images were captured by a CCD camera embedded in the imaging system and analyzed by the Lumina II Living Imaging 4 software [29].

\subsection{Statistical analysis}

All data are presented as the mean \pm SEM for repeats twice of each experiment. Statistical analysis was conducted using SPSS 19.0 (IBM Corp.). A t-test was used to examine whether the DI of each group was significantly different from the chance level (50\%). The statistical analysis was conducted by oneway ANOVA, followed by Bonferroni's post-hoc test, and $p<0.05$ was considered to indicate a statistically significant difference.

\section{Results}

\subsection{MOTS-c facilitates the formation and consolidation of object recognition memory}

In NOR task, when TET was $5 \mathrm{~s}$ in the training phase and memory was examined after $24 \mathrm{~h}$, the control group could not distinguish the novel object from the familiar object. However, i.c.v. administration of MOTS-c ( $5 \mu \mathrm{g} /$ mouse, i.c.v.) showed good memory performance for the familiar one (T-test: $p<0.01$ for MOTS-c group, one-way ANOVA: $p<0.05$ for control group vs MOTS-c group, Fig $1 \mathrm{~A}$ ), indicating that MOTS-c facilitates the formation of object memory. When TET was extended to $10 \mathrm{~s}$ in the training phase and memory was tested after $24 \mathrm{~h}$, both control and MOTS-c ( $5 \mu \mathrm{g} /$ mouse, i.c.v.) groups showed good memory performance (T-test: $p<0.01$ for control group, $p<0.01$ for MOTS-c group, Fig 1B). In this case, it is difficult to identify whether MOTS-c has a memory enhancement effect in the object recognition memory retention. This difference may reflect the existence of a ceiling effect of MOTS-c. Thus, according to the article[30], we have used an extended interval of 3 days. The results showed that control group failed to make a distinction between the novel object and the familiar one. While MOTS-c-treated mice still showed good memory performance (T-test: $p<0.01$ for MOTS-c group, one-way ANOVA: $p<$ 0.05 for control group vs MOTS-c group, Fig $1 C$ ), indicating that MOTS-c prolongs the consolidation of object recognition memory.

Meanwhile, MOTS-c ( $1 \mu \mathrm{g} / \mathrm{mouse}$, iCA1) was injected into the bilateral hippocampus of mice to facilitate the formation of object recognition memory (T-test: $p<0.01$ for MOTS-c group, one-way ANOVA: $p<0.01$ for control group vs MOTS-c group, Fig 1D). In regarding to the consolidation of object recognition memory, MOTS-c $(1 \mu \mathrm{g} /$ mouse, iCA1) also showed similar effects with i.c.v. injection (T-test: $p$ 
$<0.01$ for both control group and MOTS-c group, Fig 1E; T-test: $p<0.01$ for MOTS-c group, one-way ANOVA: $p<0.05$ for control group vs MOTS-c group, Fig 1F).

\subsection{MOTS-c facilitates the formation and consolidation of object location recognition memory}

Similarly, in OLR task, when TET was $5 \mathrm{~s}$ in the training period and memory was tested after $24 \mathrm{~h}$, control group failed to distinguish between novel location and familiar location. Whereas MOTS-c (5 $\mu \mathrm{g} /$ mouse, i.c.v.) group showed good memory performance for the familiar one (T-test: $p<0.01$ for MOTS-c group, one-way ANOVA: $p<0.05$ for control group vs MOTS-c group, Fig $2 A$ ), indicating that MOTS-c facilitates the formation of location recognition memory. Besides, when TET was $10 \mathrm{~s}$ and memory was tested after $24 \mathrm{~h}$, both control and MOTS-c ( $5 \mu \mathrm{g} / \mathrm{mouse}$, i.c.v.) groups was able to distinguish the novel object location and the familiar one (T-test: $p<0.01$ for control group, $p<0.001$ for MOTS-c group, Fig 2B). When TET was $10 \mathrm{~s}$ in the training phase and memory was tested 3 days after training, control group failed to make a distinction between the novel location and the familiar one, while MOTS-c $(5 \mu \mathrm{g} /$ mouse, i.c.v.) group still showed a good memory performance (T-test: $p<0.01$ for MOTS-c group, one-way ANOVA: $p<0.01$ for control group vs MOTS-c group, Fig $2 \mathrm{C}$ ), indicating that MOTS-c prolongs the consolidation of location recognition memory.

Likewise, MOTS-c ( $1 \mu \mathrm{g} /$ mouse, iCA1) was infused into the bilateral hippocampus of mice to facilitate the formation of location recognition memory (T-test: $p<0.01$ for MOTS-c group, one-way ANOVA: $p<0.05$ for control group vs MOTS-c group, Fig 2D). For the consolidation of location recognition memory, MOTS-c $(1 \mu \mathrm{g} /$ mouse, iCA1) also showed similar effects with i.c.v. injection (T-test: $p<0.01$ for control group, $p<0.001$ for MOTS-c group, Fig 2E; T-test: $p<0.01$ for MOTS-c group, one-way ANOVA: $p<$ 0.05 for control group vs MOTS-c group, Fig $2 \mathrm{~F}$ ).

\subsection{MOTS-c improves $A \beta_{1-42}$ or LPS induced memory impairment through AMPK pathway}

In NOR and OLR task, when the TET was $10 \mathrm{~s}$ in the training period and memory was tested after 24 $h$, control group could discriminate the novel object or novel location from the familiar one, with the DI (64.3\% for NOR, $61.9 \%$ for OLR) being significantly higher than the $50 \%$ chance level (T-test: $p<0.01$ for control group both in NOR and OLR, Fig $3 A$ and $3 B$ ), but I.c.v. injection of $A \beta_{1-42}(800 \mathrm{pmol} / \mathrm{mouse}$, i.c.v.) significantly disrupted object or location recognition memory, the average DI of these groups $(51.6 \%$ for NOR, $51.8 \%$ for OLR) was significantly lower than that of control group (one-way ANOVA: $p<0.05$ for control group vs $A \beta_{1-42}$ group both in NOR and OLR, Fig $3 A$ and $3 B$ ). MOTS-c treatment ( $5 \mu \mathrm{g} / \mathrm{mouse}$, i.c.v.) significantly alleviated $A \beta_{1-42}$ induced the object or location recognition memory deficits (T-test: $p<$ 0.01 for $A \beta_{1-42}+$ MOTS-c group in NOR, and $p<0.05$ for $A \beta_{1-42}+$ MOTS-c group in OLR; one-way ANOVA: $p<0.05$ for $A \beta_{1-42}$ group vs $A \beta_{1-42}+$ MOTS-c group both in NOR and OLR, Fig $3 A$ and $3 B$ ). When dorsomorphin, an inhibitor of the AMPK signaling pathway, was pre-injected, these memory improvement effects of MOTS-c were blocked by dorsomorphin (one-way ANOVA: $p<0.05$ for A $\beta_{1-42}+$ MOTS-c group vs $A \beta_{1-42}+$ dorsomorphin + MOTS-c group both in NOR and OLR, Fig $3 A$ and $3 B$ ). 
In addition, according to some publication, LPS is a widely used model of memory impairment[3133]. Firstly, we preferentially explore the dose range from $1 \mu \mathrm{g} / \mathrm{mouse}, 2 \mu \mathrm{g} / \mathrm{mouse}$ to $4 \mu \mathrm{g} / \mathrm{mouse}$ in the dose selection of i.c.v. injection. It was found that i.c.v. injection of LPS impaired object recognition memory in mice at the doses of $2 \mu \mathrm{g} /$ mouse and $4 \mu \mathrm{g} /$ mouse, and $1 \mu \mathrm{g} /$ mouse did not work. While 4 $\mu \mathrm{g} /$ mouse impaired object recognition memory accompanied by a decrease in body weight (one-way ANOVA: $p<0.01$ compared with control in NOR, Fig 3C). Therefore, we selected $2 \mu \mathrm{g} /$ mouse in subsequent experiments. As shown in Fig 3D and 3E, in NOR and OLR tasks, the TET was $10 \mathrm{~s}$ and memory was tested after $24 \mathrm{~h}$, control group could discriminate the novel object or new location from the familiar one, with the DI (59.7\% for NOR, 63.1 for OLR) being significantly higher than the $50 \%$ chance level (T-test: $p<0.01$ for control group both in NOR and OLR, Fig 3D and 3E). LPS ( $2 \mu \mathrm{g} /$ mouse, i.c.v.) treatment significantly disrupted memory, the average DI of this group ( $50.9 \%$ for NOR, $51.1 \%$ for OLR) was significantly lower than that of control group (one-way ANOVA: $p<0.01$ for control group vs $A \beta_{1-42}$ group both in NOR and OLR, Fig 3D and 3E). MOTS-c treatment ( $5 \mu \mathrm{g} /$ mouse, i.c.v.) significantly alleviated the object or location recognition memory-impairing effects of LPS (T-test: $p<0.001$ for $A \beta_{1-42}$ + MOTS-c group in NOR, and $p<0.01$ for $A \beta_{1-42}+$ MOTS-c group in OLR; one-way ANOVA: $p<0.05$ for $A \beta_{1-42}$ group vs $A \beta_{1-42}+$ MOTS-c group both in NOR and OLR, Fig 3D and 3E). Likewise, when dorsomorphin was pre-injected, these memory improvement effects of MOTS-c were blocked by dorsomorphin (one-way ANOVA: $p<0.01$ for $A \beta_{1-42}+$ MOTS-c group vs $A \beta_{1-42}+$ dorsomorphin + MOTS-c group in NOR, $p<0.05$ for $A \beta_{1-42}+$ MOTS-c group vs $A \beta_{1-42}+$ dorsomorphin + MOTS-c group in OLR, Fig $3 \mathrm{D}$ and $3 \mathrm{E})$.

To determine the mechanism of MOTS-c in the object or location recognition memory deficits, we further investigated the expression of AMPK and MAPK signaling pathways by western blotting. As shown in Fig 4, MOTS-c treatment significantly up-regulated the phosphorylation of AMPK in hippocampus (one-way ANOVA: $p<0.05$ for $A \beta_{1-42}$ group vs $A \beta_{1-42}+$ MOTS-c group, $p<0.01$ for LPS group vs LPS + MOTS-c group, Fig 4), while it did not influence the phosphorylation of ERK, JNK and p38 in hippocampus. In summary, these data suggest that MOTS-c attenuates $A \beta_{1-42}$ or LPS-induced object or location recognition memory deficits, which are involved in AMPK system.

\subsection{MOTS-c reduces pro-inflammatory factors production and inhibits microglia and astrocyte activation}

Subsequently, to determine whether the memory improvement effect of MOTS-c is associated with inhibition of neuroinflammation, we investigated the expression levels of pro-inflammation factors in mouse hippocampus. As shown in Fig 5A and 5B, RT-qPCR experiment results showed that the expression levels of IL-6, IL-1 $\beta$, TNF- $\alpha$, COX-2 and iNOS mRNA were dramatically increased in hippocampus after $A \beta_{1-42}$ or LPS treatment $\left(p<0.01\right.$ and $p<0.001$ for control group vs $A \beta_{1-42}$ or LPS group, Fig $5 \mathrm{~A}$ and $5 \mathrm{~B})$. MOTS-c treatment ( $5 \mu \mathrm{g} /$ mouse, i.c.v.) significantly decreased expression levels of IL-1 $\beta$, IL-6, TNF- $a$, COX-2 and iNOS mRNA $\left(p<0.01\right.$ and $p<0.001$ for $A \beta_{1-42}$ or LPS group vs $A \beta_{1-42}+$ 
MOTS-c or LPS + MOTS-c group, Fig 5A and 5B). The protein levels of TNF-a, IL- 6 and IL-1 $\beta$ were determined by western blotting and elisa assay. As shown in Fig $5 \mathrm{C}-5 \mathrm{H}$, similar to RT-qPCR results, western blotting and elisa assay results showed that the expression levels of TNF- $a$, IL-1 $\beta$ and IL- 6 were dramatically increased in the hippocampus after mice were subjected to A $\beta_{1-42}$ or LPS $(p<0.01$ and $p<$ 0.001 for control group vs $A \beta_{1-42}$ or LPS group, Fig $5 \mathrm{C}-5 \mathrm{H}$ ). MOTS-c treatment ( $5 \mu \mathrm{g} / \mathrm{mouse}$, i.c.v.) significantly decreased expression of IL-1 $\beta$, IL- 6 and TNF- $\alpha$ in the hippocampus of mice $(p<0.05$ and $p<$ 0.001 for $A \beta_{1-42}$ or LPS group vs $A \beta_{1-42}+$ MOTS-c or LPS + MOTS-c group, $5 \mathrm{C}-5 \mathrm{H}$ ).

Overall, all data is analyzed by one-way ANOVA followed by bonferroni's post-hoc test, and these results indicate that MOTS-c reduced $A \beta_{1-42}$ or LPS-induced production of pro-inflammatory cytokines. Then, to confirm whether MOTS-c have an influence on the activation of glial cells such as astrocyte and microglia, immunofluorescent staining for GFAP and CD11b+, markers of astrocyte and microglia, was performed in hippocampus of mice. As shown in Fig 6 and 7, LPS $(2 \mu \mathrm{g} / \mathrm{mouse}$, i.c.v. $)$ significantly increased the number of GFAP and CD11b+ positive neurons, while MOTS-c treatment ( $5 \mu \mathrm{g} / \mathrm{mouse}$, i.c.v.) decreased the expression of both markers, suggesting MOTS-c inhibited the activation of microglia and astrocytes induced by LPS in mice (Fig 6 and 7).

\subsection{Evaluation of MOTS-c into BBB}

Non-invasive application of biomacromolecules such as proteins and peptides has been more and more important. Central direct administration is not a possible method for patients with central nervous system diseases. Thus, in NOR task, we explored the effects of peripheral administration of MOTS-c on memory formation, memory consolidation and memory impairment in mice. As shown in Fig 8A, when TET was $5 \mathrm{~s}$ in the training phase and memory was examined after $24 \mathrm{~h}$, the control group could not distinguish the novel object from the familiar object, while i.c.v. administration of MOTS-c $(5 \mu \mathrm{g} / \mathrm{mouse})$ showed good memory performance for the familiar one (one-way ANOVA: $p<0.001$ for control group vs i.c.v. MOTS-c group, Fig $8 \mathrm{~A}$ ). Nasal drip of MOTS-c (50 $\mu \mathrm{g} /$ mouse, i.n.) could not make a distinction between the novel object and the familiar one (one-way ANOVA: $p<0.05$ for i.c.v. MOTS-c group vs i.n. MP group, Fig 8A). Subsequently, when TET was $10 \mathrm{~s}$ in the training phase and memory was examined after $72 \mathrm{~h}$, the control group or i.n. administration of MOTS-c ( $50 \mu \mathrm{g} / \mathrm{mouse})$ could not distinguish the novel object from the familiar object. However, i.c.v. administration of MOTS-c ( $5 \mu \mathrm{g} / \mathrm{mouse})$ showed good memory performance (one-way ANOVA: $p<0.01$ for control group vs i.c.v. MOTS-c group, or i.c.v. MOTS-c group vs i.n. MOTS-c group, Fig 8B). When the TET was $10 \mathrm{~s}$ and memory was tested after $24 \mathrm{~h}$, in the LPS-induced memory impairment model, control group or MOTS-c (i.c.v.) group could discriminate the novel object from the familiar one, while i.n. administration of MOTS-c ( $50 \mu \mathrm{g} / \mathrm{mouse}$, i.n.) still significantly disrupted memory (one-way ANOVA: $p<0.05$ for control group vs LPS group or LPS group vs LPS + i.c.v. MOTS-c group, or $p<0.01$ for LPS + i.c.v. MOTS-c group vs LPS + i.n. MOTS-c group, Fig $8 C)$.

Indditionally, we first want to know whether MOTS-c has a transmembrane function in vitro. Firstly, the $\mathrm{N}$-terminus of MOTS-c was labeled with FITC and BV2 and U87 cells were selected as in vitro models to 
identify MOTS-c transmembrane activity. As shown in Fig S4 and S5, similar to the control or FITC group results in BV-2 and U87 cells, FITC labeled MOTS-c did not show any fluorescence. Fluorescence was not observed when the concentration of MOTS-c was increased to $20 \mu \mathrm{M}$, suggesting that MOTS-c does not have transmembrane activity in BV-2 and U87 cells. Therefore, in subsequent experiments, we will screen for appropriate cell-penetrating peptides as a carrier for MOTS-c into the brain.

\subsection{Screening of brain-targeted cell penetrating peptides}

According to the previous reports on brain-targeting cell-penetrating peptides[34, 35], we selected and synthesized 7 CPPs with good transmembrane effect (Table 4 and 5). Table 4 showed the sequence of all cell penetrating peptides, and table 5 showed the purity and molecular weight of all cell penetrating peptides. All the peptides in this paper were synthesized by the standard Fmoc-chemistry-based strategy. The mass spectrometry and HPLC chromatogram of CPPs is shown in supplementary material.

Table 4. The name and sequence of FITC-labeled cell penetrating peptides (CPPs).

\begin{tabular}{|c|c|}
\hline CPPs name & CPPs sequence \\
\hline 口FITC-Acp-(PRR) $)_{3}$ & FITC-Acp-PRRPRRPRR \\
\hline 口FITC-Acp-(PRR) ${ }_{5}$ & FITC-Acp-PRRPRRPRRPRRPRR \\
\hline GFITC-Acp-TAT & FITC-Acp-YGRKKRRQRRR \\
\hline IFITC-Acp-SynB ${ }_{3}$ & FITC-Acp-RRLSYSRRRF \\
\hline QFITC-Acp-Antp & FITC-Acp-RQIKIWFQNRRMKWKKK \\
\hline 口FITC-Acp-T7 & FITC-Acp-HAIYPRH \\
\hline IFITC-Acp-Hoax 13 & FITC-Acp-RQVTIWFQNRRVKEKK \\
\hline
\end{tabular}

Table 5. The purity and molecular weight of cell penetrating peptide.

\begin{tabular}{|c|c|c|}
\hline CPPs & Purity (HPLC) & Molecular weight $(\mathrm{g} / \mathrm{mol})$ \\
\hline 口FITC-Acp-(PRR) ${ }_{3}$ & $99.61 \%$ & 1749.98 \\
\hline aFITC-Acp-(PRR) ${ }_{5}$ & $98.77 \%$ & 2568.35 \\
\hline aFITC-Acp-TAT & $97.41 \%$ & 2062.04 \\
\hline aFITC-Acp-SynB ${ }_{3}$ & $99.13 \%$ & 1898.88 \\
\hline aFITC-Acp-Antp & $99.04 \%$ & 2749.73 \\
\hline DFITC-Acp-T7 & $99.09 \%$ & 1395.56 \\
\hline DFITC-Acp-Hoax 13 & $99.19 \%$ & 2618.31 \\
\hline
\end{tabular}


Laser confocal and flow cytometry experiments showed that the transmembrane ability of (PRR) 5 and Antp was superior to that of other CPPs in BV2 and U87 cells (Fig 8A-8D). The cytotoxicity of (PRR) $)_{5}$ and Antp at different doses was evaluated with the MTT assay. As shown in Fig 8E-8F, it is worth noting that the cell viability of Antp at the concentration of $100 \mu \mathrm{M}$ was $82 \%$ in U87, while (PRR) ${ }_{5}$ didn't show any significant cytotoxicity at different doses compared to $100 \%$. Therefore, (PRR) $)_{5}$ is more suitable as a carrier for MOTS-c into the brain than Antp.

\subsection{Central pharmacological activity and targeting after peripheral administration of a cell-penetrating MOTS analog (MP)}

A 6-aminohexanoic acid (AcP) was added to the N-terminus of (PRR) $)_{5}$ for ligation of MOTS-c by solid phase peptide synthesis. Based on the first word of the two peptides, we temporarily refer to the synthesized new molecule as MP. Synthetic methods, mass spectrometry and HPLC chromatograms are displayed in supplemental materials. Then in NOR task, we explored the effects of MP on memory formation, memory consolidation and memory impairment in mice after nasal administration (i.n.) or intravenous injection (i.v.).

As shown in Fig 10A, when TET was $5 \mathrm{~s}$ in the training phase and memory was examined after $24 \mathrm{~h}$, the control group could not distinguish the novel object from the familiar object. As the result shown in Fig 8, i.c.v. administration of MOTS-c (5 $\mu \mathrm{g} /$ mouse, i.c.v.) showed good memory performance for the familiar one (T-test: $p<0.001$ for MOTS-c group, Fig 10A). Subsequently, i.n. administration of MOTS-c ( $50 \mu \mathrm{g} /$ mouse, i.n.) or i.v. administration of MOTS-c ( $50 \mu \mathrm{g} / \mathrm{mouse}$, i.v.) could not make a distinction between the novel object and the familiar one, while i.n. administration of MP (50 $\mu \mathrm{g} / \mathrm{mouse}$, i.n.) or i.v. administration of MP $(50 \mu \mathrm{g} /$ mouse, i.v.) showed good memory performance (T-test: $p<0.001$ for both i.n. MP group and i.v. MP group; one-way ANOVA: $p<0.05$ for i.n. MOTS-c group vs i.n. MP group, or i.v. MOTS-c group vs i.v. MP group, Fig 10A). The results of the memory consolidation experiment are similar to those of memory formation. When TET was $10 \mathrm{~s}$ in the training phase and memory was examined after 72 h, i.c.v. administration of MOTS-c ( $5 \mu \mathrm{g} /$ mouse, i.c.v.), i.n. administration of MP ( $50 \mu \mathrm{g} / \mathrm{mouse}$, i.n.) or i.v. administration of MP ( $50 \mu \mathrm{g} /$ mouse, i.v. $)$ showed good memory performance, but not i.n. administration of MOTS-c or i.v. administration of MOTS-c group (T-test: $p<0.01$ for i.c.v. MOTS-c group, i.n. MP group and i.v. MP group; one-way ANOVA: $p<0.05$ for i.n. MOTS-c group vs i.n. MP group, or i.v. MOTS-c group vs i.v. MP group, Fig 10B).

When the TET was $10 \mathrm{~s}$ and memory was tested after $24 \mathrm{~h}$, in the LPS-induced memory impairment model, i.c.v. injection of MOTS-c, i.n. administration of MP $(50 \mu \mathrm{g} / \mathrm{mouse}$, i.n. $)$ or i.v. administration of MP $(50 \mu \mathrm{g} / \mathrm{mouse}$, i.v.) could discriminate the novel object from the familiar one, while i.n. administration of MOTS-c ( $50 \mu \mathrm{g} /$ mouse, i.n.) or i.v. administration of MOTS-c ( $50 \mu \mathrm{g} / \mathrm{mouse}$, i.v.) still significantly disrupted memory (T-test: $p<0.01$ for control group and LPS + i.v. MP, and $p<0.001$ for LPS + i.c.v. MOTS-c group and LPS + i.n. MP group; one-way ANOVA: $p<0.05$ for LPS + i.n. MOTS-c group vs LPS + i.n. MP group or LPS + i.v. MOTS-c group vs LPS + i.v. MP group, Fig 10C). 
To evaluate the delivery of MOTS-c and MP into the mouse brain, in vivo fluorescent microscopy and fluorescence imaging experiments were performed. In detail, after i.n. instillation or i.v. injection of RhoMOTS-c or Rho-MP $2 \mathrm{~h}$, mice were killed and perfused for removal of the residual blood in brain. The brain was removed and placed into an imaging system. Fig 9D-9l shows the real-time in vivo bio-distribution for Rho-MP. Brains from mice treated with Rho-MOTS-c or saline alone displayed no significant signal. Compared with control and Rho-MOTS-c groups, significant fluorescence signals of Rho-MP were detected in the brain by fluorescent microscopy studies ( $p<0.01$ for control group vs Rho-MP group or Rho-MOTS-c group vs Rho-MP group, Fig 9D-9F) and fluorescence imaging experiments ( $p<0.05$ for control group vs Rho-MP group, or $p<0.01$ for Rho-MOTS-c group vs Rho-MP group, Fig 9G-9l).

\section{Discussion}

MOTS-c, a 16-amino acid mitochondrial derivative peptide, was first discovered in 2015 by Cohen et al and reported to be involved in regulating insulin resistance and obesity, osteoporosis and inflammatory responses[16, 17, 19,22]. Due to the widespread distribution of MOTS in the CNS and its role in metabolism, Cohen et al. pointed out in the report that MOTS-c may be effective as a therapeutic option toward the prevention of the aging processes[16]. However, the roles of MOTS-c in the memory recognition process still remain uncertain. Therefore, the present study is the first to provide evidences that MOTS-c enhance the object recognition memory formation and consolidation in NOR task. Similarly, in OLR task, MOTS-c also facilitates the formation and consolidation of location recognition memory.

Additionally, increasing evidences suggest that neuroinflammation play multiple roles in AD progression such as inflammatory mediators, cytokines and chemokines, which might directly act on neurons to induce apoptosis[8, 9, 36]. An abundance of anti-inflammatory drugs is currently being evaluated in clinical trials of AD or mild AD, including NCT02423200, NCT02423122, NCT01009359, NCT02062099, NCT00013650 and NCT02646982. Targeting of these immune mechanisms could lead to future therapeutic or preventive strategies for AD. Interestingly, MOTS-c has a significant inhibitory effect on the expression of inflammation and immune-related genes[16, 21, 37]. Yan et al. also reported the antiinflammatory effects of MOTS-c[22]. Central injection of $A \beta_{1-42}$ or LPS evokes an inflammatory response in the brain, which have been widely used in the experimental model of $A D$ or neuroinflammation[30, 32, $38,39]$. Therefore, in this experiment, we examined the roles of MOTS-c in $A \beta_{1-42}$ or LPS-induced memory impairment. The results indicated that i.c.v. administration of $A \beta_{1-42}$ or LPS elicited object and location recognition memory deficits in mice, which is consistent with the effect of $A \beta_{1-42}$ or LPS on memory described in previous reports[30, 40]. MOTS-c application could significantly ameliorate the memory deficits induced by $A \beta_{1-42}$ or LPS in object and location recognition memory tasks, whereas dorsomorphin treatment in advance, an inhibitor of AMPK signaling pathway, significantly blocked the memory-ameliorating effects of MOTS-c in A $\beta_{1-42}$ or LPS-induced AD model. Dorsomorphin itself does not affect the memory, indicating that the roles of MOTS-c in $A \beta_{1-42}$ or LPS-induced memory-impairment may involve AMPK signaling pathway. Likewise, western blotting experiments showed that the 
phosphorylation of AMPK was significantly up-regulated in the hippocampus after MOTS-c application in LPS or $A \beta_{1-42}$-induced $A D$ model, which is in line with behavioral experiment results.

The underlying mechanism of this neuroprotection of MOTS-c may involve inhibition of the inflammatory responses of the CNS. In order to verify this hypothesis, qRT-PCR and elisa experiments were applied to evaluate the effects of MOTS-c. A series of proinflammatory cytokines including IL $-6, I L-1 \beta, T N F-a$, COX-2 and iNOS were dramatically increased in the hippocampus of LPS or $A \beta_{1-42}$-treated mice, whereas these pro-inflammatory factors were significantly down-regulated after MOTS-c treatment. Meanwhile, i.c.v. administration of LPS significantly increased markers of microglia (CD11 $\left.\mathrm{b}^{+}\right)$and astrocytes (GFAP) expression, while the expression of both markers was markedly decreased in the MOTS-c-treated mice, suggesting that MOTS-c suppressed the activation of microglia and astrocytes induced by LPS in mice brain. Taken together, these results show that MOTS-c ameliorates the memory deficit induced by $A \beta_{1-42}$ or LPS in object and location memory tasks, possibly via inhibited the microglia and astrocytes activation and reduced inflammatory processes. In addition, humanin, a mitochondrially derived peptide similar to MOTS-c, exerts anti-inflammatory and anti-apoptotic effects[41-43]. Thus, in addition to the AMPK signaling pathway, we also investigated the classical inflammatory signaling pathway (MAPK signaling pathway including ERK, JNK and p38 signal). The results showed that the phosphorylation of ERK, JNK and p38 were significantly up-regulated by LPS or A $\beta_{1-42}$ in the hippocampus, while MOTS-c treatment did not inhibit phosphorylation of them by western blotting. In general, MOTS-c attenuates $A \beta_{1-42}$ or LPS-induced memory impairments and neuroinflammation via the AMPK signaling pathway.

In recent years, mounting evidences suggests that a major challenge of macromolecular drugs including proteins and peptides for the treatment of neurodegenerative diseases is the delivery of these drugs over the blood brain barrier (BBB) $[25,34,35]$. Solanezumab's failure in the Phase III trial inspired us whether brain-targeted drugs can across blood-brain barrier is an important consideration (mainly in any dose of antibody, and ultimately only about $0.1 \%$ can penetrate the BBB to reach the brain [23]. However, in our experiments, peripheral administration of MOTS-c could not show a good memory in NOR task. In vitro cell experiments also indicate weak cell penetration of MOTS-c in BV2 and U87 cells. In order to improve the brain intake of MOTS-c, we designed and synthesized a series of brain-targeted cell penetrating peptides to screen out suitable carriers for MOTS-c into the brain. Laser confocal and flow cytometry experiments showed that the transmembrane ability of (PRR) ${ }_{5}$ and Antp was superior to that of other CPPs in BV2 and U87 cells, while the cytotoxicity of (PRR $)_{5}$ was lower than that of Antp, indicating that $(\mathrm{PRR})_{5}$ is more suitable as a carrier for MOTS-c into the brain. Subsequently, we covalently conjugated MOTS-c and (PRR) $)_{5}$ to form a new peptide, and called MP. Then in NOR task, i.n. or i.v. administration of MP showed good memory performance on memory formation, memory consolidation and memory impairment in mice, while i.n. or i.v. administration of MOTS-c could not achieve this effect, suggesting that the brain uptake rate of MP is higher than that of MOTS. Finally, to demonstrate the delivery of MP into the mouse brain, in vivo fluorescent microscopy and fluorescence imaging experiments was performed. A strong NIR fluorescent signal coming from Rho-MP was observed over the whole brain at 2 
h after i.n. instillation or i.v. injection. Brains from control mice treated with Rho-MOTS-c or saline alone displayed no significant signal. Overall, the present results suggest that MOTS-c might be a new potential target for treatment of cognitive decline in $A D$ and this way of administration MP will be the potential strategy for non-invasive therapeutic intervention.

\section{Conclusion}

To summarize, the results of the present study indicated that central injection of MOTS-c not only facilitated object and location recognition memory formation, but also prolonged memory retention in NOR and OLR tasks. Moreover, we found that i.c.v. injection of MOTS-c was able to attenuate the memory impairment induced by $A \beta_{1-42}$ or LPS, and provide neuroprotection against LPS or $A \beta_{1-42}$-induced neuroinflammation in vivo, and the mechanisms may be related with phosphorylation of AMPK. Meanwhile, i.n. instillation or i.v. injection of MP, but not MOTS-c, significantly enhances memory and ameliorates the memory deficit. Near-infrared fluorescent and confocal microscopy experiments were applied to detect the brain uptake and distribution of MOTS-c and MP. Taken all together, the present data suggest that mitochondrial derivative peptide (MOTS-c) may represent a novel treatment strategy for AD. Moreover, this way of administration MP will be a novel promising non-invasive treatment for the CNS disease.

\section{Abbreviation}

AD: Alzheimer's disease, $A \beta$ : amyloid- $\beta, C N S$ : central nervous system, sORF: open reading frame, NOR: Novel object recognition task, OLR: Object location recognition task, CPPs: cell penetrating peptides, H\&E: haematoxylin eosin staining, DI: Discrimination index, TET: total exploration time, WB : western blotting, PVDF : polyvinylidene fluoride, RT-qPCR: real time quantitative polymerase chain reaction, ELISA : enzyme-linked immunoassay, GFAP: glial fibrillary acidic protein, FITC: fluorescein isothiocyanate, Rho: Rhodamine B, IL-6: interleukin-6, IL-1ß: interleukin 1 beta, TNF-a: tumor necrosis factor alpha, COX-2: cyclooxygenase -2 , iNOS: inducible nitric oxide synthase, AMPK: AMP-activated protein kinase, MAPK: mitogen-activated protein kinase, BBB: blood brain barrier, MP: MOTS-c-acp-(PRR) ${ }_{5}$, LPS:

lipopolysaccharide, CNS: Central nervous system, i.n.: intranasal, i.v.: intravenous, i.c.v.: intracerebroventricular, DMSO: Dimethyl sulfoxide.

\section{Declarations}

\section{Acknowledgement}

We are grateful for the grants from the National Natural Science Foundation of China, the Program for Ministry of Education "Peptide Drugs" Innovation Team and the Fundamental Research Funds for the Central Universities. 


\section{Funding}

This work was supported by the National Natural Science Foundation of China (No. 21432003), and Natural Science Foundation of Gansu Province (No. 18JR3RA280) the Fundamental Research Funds for the Central Universities (No. Izujbky-2017-148).

\section{Authors' contributions}

JinHong Jiang, Xin Chang, YaoYan Nie and YuXuan Shen conducted the experiments, performed the analysis. Xin Chang and KangTai Xu analyzed the data and imaging and provided peptides drugs. XueYa Liang and YaLi Peng facilitated the equipment and software to perform the behavior experiments. JinHong Jiang and Min Chang designed the experiments and contributed to writing and editing the manuscript. All authors read and approved the final manuscript.

\section{Availability of data and materials}

The data used or analyzed in this study are available from the corresponding author on reasonable request.

\section{Ethics approval and consent to participate}

All of the procedures in this experiment were approved by the Ethics Committee of Lanzhou University, China (permit number: SYXK Gan 2009-0005).

\section{Consent for publication}

Not Applicable

\section{Competing interests}

The authors have no conflicts of interest to declare.

\section{References}

1.Sadigh-Eteghad S, Sabermarouf B, Majdi A, Talebi M, Farhoudi M, Mahmoudi J: Amyloid-beta: a crucial factor in Alzheimer's disease. Med Princ Pract 2015, 24:1-10.

2.Jha MK, Park DH, Kook H, Lee IK, Lee WH, Suk K: Metabolic Control of Glia-Mediated Neuroinflammation. Curr Alzheimer Res 2016, 13:387-402. 
3.Loera-Valencia R, Cedazo-Minguez A, Kenigsberg PA, Page G, Duarte Al, Giusti P, Zusso M, Robert P, Frisoni GB, Cattaneo A, et al: Current and emerging avenues for Alzheimer's disease drug targets. J Intern Med 2019, 286:398-437.

4.Guo C, Sun L, Chen X, Zhang D: Oxidative stress, mitochondrial damage and neurodegenerative diseases. Neural Regen Res 2013, 8:2003-2014.

5.Kerr JS, Adriaanse BA, Greig NH, Mattson MP, Cader MZ, Bohr VA, Fang EF: Mitophagy and Alzheimer's Disease: Cellular and Molecular Mechanisms. Trends Neurosci 2017, 40:151-166.

6.Fang EF, Hou Y, Palikaras K, Adriaanse BA, Kerr JS, Yang B, Lautrup S, Hasan-Olive MM, Caponio D, Dan $X$, et al: Mitophagy inhibits amyloid-beta and tau pathology and reverses cognitive deficits in models of Alzheimer's disease. Nat Neurosci 2019, 22:401-412.

7.Lanzillotta C, Di Domenico F, Perluigi M, Butterfield DA: Targeting Mitochondria in Alzheimer Disease: Rationale and Perspectives. CNS Drugs 2019.

8.Wang H, Shen Y, Chuang H, Chiu C, Ye Y, Zhao L: Neuroinflammation in Alzheimer's Disease: Microglia, Molecular Participants and Therapeutic Choices. Curr Alzheimer Res 2019, 16:659-674.

9.Finneran DJ, Nash KR: Neuroinflammation and fractalkine signaling in Alzheimer's disease. $J$ Neuroinflammation 2019, 16:30.

10.Dionisio-Santos DA, Olschowka JA, O'Banion MK: Exploiting microglial and peripheral immune cell crosstalk to treat Alzheimer's disease. J Neuroinflammation 2019, 16:74.

11.Fan Z, Brooks DJ, Okello A, Edison P: An early and late peak in microglial activation in Alzheimer's disease trajectory. Brain 2017, 140:792-803.

12.Lue LF, Beach TG, Walker DG: Alzheimer's Disease Research Using Human Microglia. Cells 2019, 8.

13.Sofroniew MV, Vinters HV: Astrocytes: biology and pathology. Acta Neuropathol 2010, 119:7-35.

14.Verkhratsky A, Olabarria M, Noristani HN, Yeh CY, Rodriguez JJ: Astrocytes in Alzheimer's disease. Neurotherapeutics 2010, 7:399-412.

15.Fu W, Shi D, Westaway D, Jhamandas JH: Bioenergetic mechanisms in astrocytes may contribute to amyloid plaque deposition and toxicity. J Biol Chem 2015, 290:12504-12513.

16.Lee C, Zeng J, Drew BG, Sallam T, Martin-Montalvo A, Wan J, Kim SJ, Mehta H, Hevener AL, de Cabo R, Cohen P: The mitochondrial-derived peptide MOTS-c promotes metabolic homeostasis and reduces obesity and insulin resistance. Cell Metab 2015, 21:443-454.

17.Lee C, Kim KH, Cohen P: MOTS-c: A novel mitochondrial-derived peptide regulating muscle and fat metabolism. Free Radic Biol Med 2016, 100:182-187. 
18.Zarse K, Ristow M: A mitochondrially encoded hormone ameliorates obesity and insulin resistance. Cell Metab 2015, 21:355-356.

19.Hu BT, Chen WZ: MOTS-c improves osteoporosis by promoting osteogenic differentiation of bone marrow mesenchymal stem cells via TGF-beta/Smad pathway. Eur Rev Med Pharmacol Sci 2018, 22:7156-7163.

20.Li H, Ren K, Jiang T, Zhao GJ: MOTS-c attenuates endothelial dysfunction via suppressing the MAPK/NF-kappaB pathway. Int J Cardio/ 2018, 268:40.

21.Zhai D, Ye Z, Jiang Y, Xu C, Ruan B, Yang Y, Lei X, Xiang A, Lu H, Zhu Z, et al: MOTS-c peptide increases survival and decreases bacterial load in mice infected with MRSA. Mol Immunol 2017, 92:151-160.

22.Yan Z, Zhu S, Wang H, Wang L, Du T, Ye Z, Zhai D, Zhu Z, Tian X, Lu Z, Cao X: MOTS-c inhibits Osteolysis in the Mouse Calvaria by affecting osteocyte-osteoclast crosstalk and inhibiting inflammation. Pharmacol Res 2019, 147:104381.

23.Panza F, Seripa D, Lozupone M, Solfrizzi V, Imbimbo BP, Barulli MR, Tortelli R, Capozzo R, Bisceglia P, Dimitri A, et al: The potential of solanezumab and gantenerumab to prevent Alzheimer's disease in people with inherited mutations that cause its early onset. Expert Opin Biol Ther 2018, 18:25-35.

24. Heitz F, Morris MC, Divita G: Twenty years of cell-penetrating peptides: from molecular mechanisms to therapeutics. Br J Pharmacol 2009, 157:195-206.

25.Guidotti G, Brambilla L, Rossi D: Cell-Penetrating Peptides: From Basic Research to Clinics. Trends Pharmacol Sci 2017, 38:406-424.

26.Jiang J, Peng Y, He Z, Wei L, Jin W, Wang X, Chang M: Intrahippocampal injection of Cortistatin-14 impairs recognition memory consolidation in mice through activation of sst2, ghrelin and GABAA/B receptors. Brain Res 2017, 1666:38-47.

27.Paxinos G, Franklin KBJ, Franklin KBJ: The mouse brain in stereotaxic coordinates. 2nd edn. San Diego: Academic Press; 2001.

28.Jiang JH, He Z, Peng YL, Jin WD, Wang Z, Mu LY, Chang M, Wang R: Phoenixin-14 enhances memory and mitigates memory impairment induced by Abeta1-42 and scopolamine in mice. Brain Res 2015, 1629:298-308.

29.Liu H, Zhang W, Ma L, Fan L, Gao F, Ni J, Wang R: The improved blood-brain barrier permeability of endomorphin-1 using the cell-penetrating peptide synB3 with three different linkages. Int J Pharm 2014, 476:1-8.

30.Han RW, Zhang RS, Xu HJ, Chang M, Peng YL, Wang R: Neuropeptide S enhances memory and mitigates memory impairment induced by MK801, scopolamine or Abeta(1)(-)(4)(2) in mice novel object 
and object location recognition tasks. Neuropharmacology 2013, 70:261-267.

31.Vasconcelos AR, Yshii LM, Viel TA, Buck HS, Mattson MP, Scavone C, Kawamoto EM: Intermittent fasting attenuates lipopolysaccharide-induced neuroinflammation and memory impairment. $J$ Neuroinflammation 2014, 11:85.

32.Zakaria R, Wan Yaacob WM, Othman Z, Long I, Ahmad AH, Al-Rahbi B: Lipopolysaccharide-induced memory impairment in rats: a model of Alzheimer's disease. Physiol Res 2017, 66:553-565.

33.Kim YE, Hwang CJ, Lee HP, Kim CS, Son DJ, Ham YW, Hellstrom M, Han SB, Kim HS, Park EK, Hong JT: Inhibitory effect of punicalagin on lipopolysaccharide-induced neuroinflammation, oxidative stress and memory impairment via inhibition of nuclear factor-kappaB. Neuropharmacology 2017, 117:21-32.

34.Cho CF, Wolfe JM, Fadzen CM, Calligaris D, Hornburg K, Chiocca EA, Agar NYR, Pentelute BL, Lawler SE: Blood-brain-barrier spheroids as an in vitro screening platform for brain-penetrating agents. Nat Commun 2017, 8:15623.

35.Bohmova E, Machova D, Pechar M, Pola R, Venclikova K, Janouskova O, Etrych T: Cell-penetrating peptides: a useful tool for the delivery of various cargoes into cells. Physiol Res 2018, 67:S267-S279.

36.Cai Z, Hussain MD, Yan LJ: Microglia, neuroinflammation, and beta-amyloid protein in Alzheimer's disease. Int J Neurosci 2014, 124:307-321.

37.Yang Y, Gao H, Zhou H, Liu Q, Qi Z, Zhang Y, Zhang J: The role of mitochondria-derived peptides in cardiovascular disease: Recent updates. Biomed Pharmacother 2019, 117:109075.

38.Catorce MN, Gevorkian G: LPS-induced Murine Neuroinflammation Model: Main Features and Suitability for Pre-clinical Assessment of Nutraceuticals. Curr Neuropharmacol 2016, 14:155-164.

39.Kasza A, Penke B, Frank Z, Bozso Z, Szegedi V, Hunya A, Nemeth K, Kozma G, Fulop L: Studies for Improving a Rat Model of Alzheimer's Disease: Icv Administration of Well-Characterized beta-Amyloid 142 Oligomers Induce Dysfunction in Spatial Memory. Molecules 2017, 22.

40.Park SJ, Jung HJ, Son MS, Jung JM, Kim DH, Jung IH, Cho YB, Lee EH, Ryu JH: Neuroprotective effects of INM-176 against lipopolysaccharide-induced neuronal injury. Pharmacol Biochem Behav 2012, 101:427-433.

41.Guo B, Zhai D, Cabezas E, Welsh K, Nouraini S, Satterthwait AC, Reed JC: Humanin peptide suppresses apoptosis by interfering with Bax activation. Nature 2003, 423:456-461.

42.Zhao ST, Zhao L, Li JH: Neuroprotective Peptide humanin inhibits inflammatory response in astrocytes induced by lipopolysaccharide. Neurochem Res 2013, 38:581-588. 


\section{Figures}
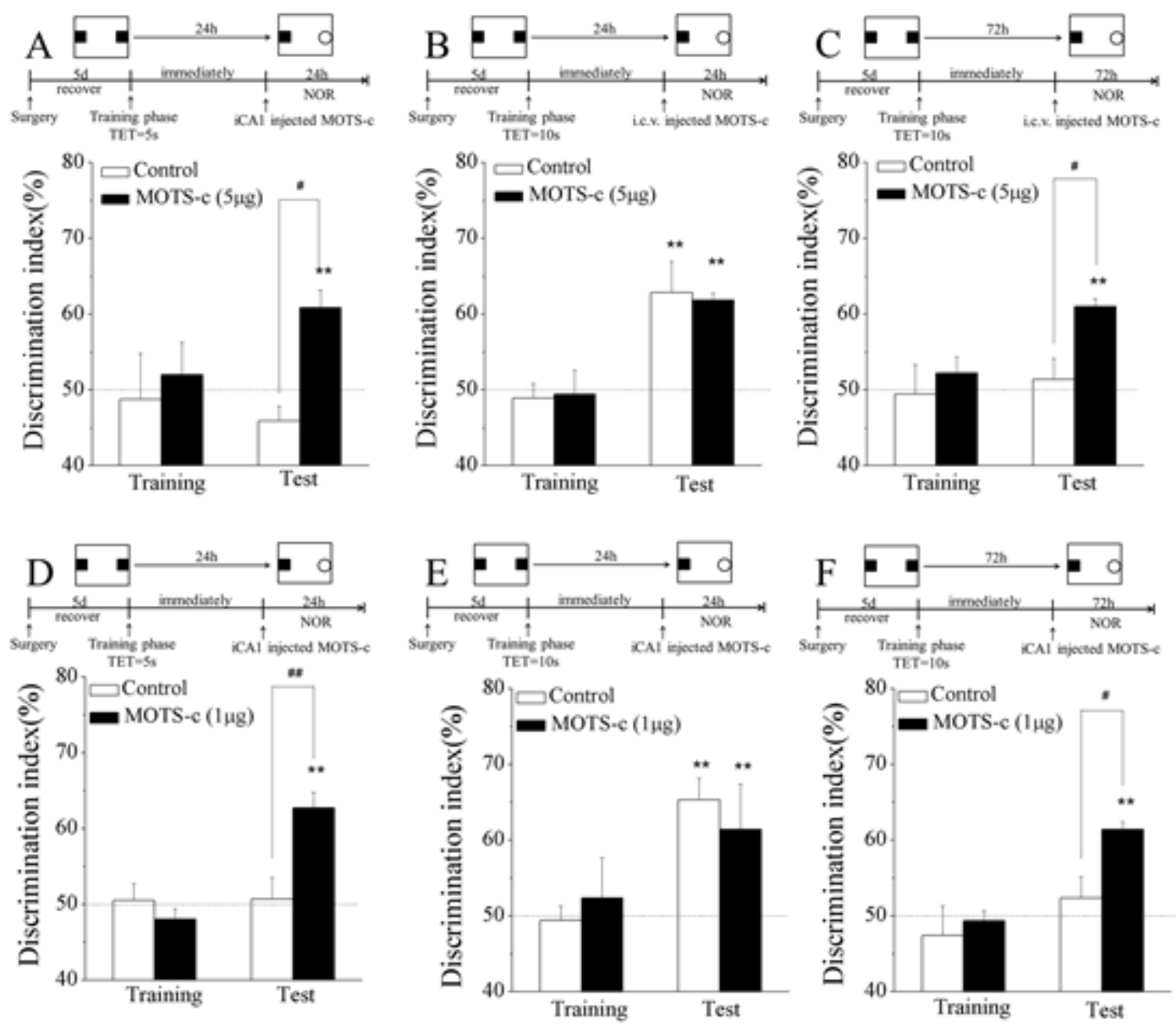

Figure 1

Central injection MOTS-c promotes the formation and consolidation of object recognition memory. In NOR task, when TET was $5 \mathrm{~s}$ and the mice were tested after 24 h, i.c.v. injection (A) or intrahippocampal CA1 microinjection of MOTS-C (D) immediately after training showed a good memory performance, whereas the control group had a poor memory rate, close to the $50 \%$ random level. (B and E) When TET was $10 \mathrm{~s}$, and the mice were tested after $24 \mathrm{~h}$, the control group and MOTS-c group (i.c.v. and iCA1) showed good object recognition memory. ( $C$ and F) When TET was $10 \mathrm{~s}$, and the mice were tested after $72 \mathrm{~h}$, the control group failed to distinguish between novel object and familiar one, whereas MOTS-c group (i.c.v. and iCA1) showed good object recognition memory. One-way ANOVA analysis displayed that there was a significant difference compared with the control mice. The dashed line indicates $50 \%$ chance level. $n=7-11$ mice per group. Vertical lines represent mean \pm SEM. T-test: ${ }^{\star *} p<0.01$ compared with $50 \%$ chance level. One-way ANOVA: \#p $<0.05$ and \#\#p $<0.01$ compared with control group. 

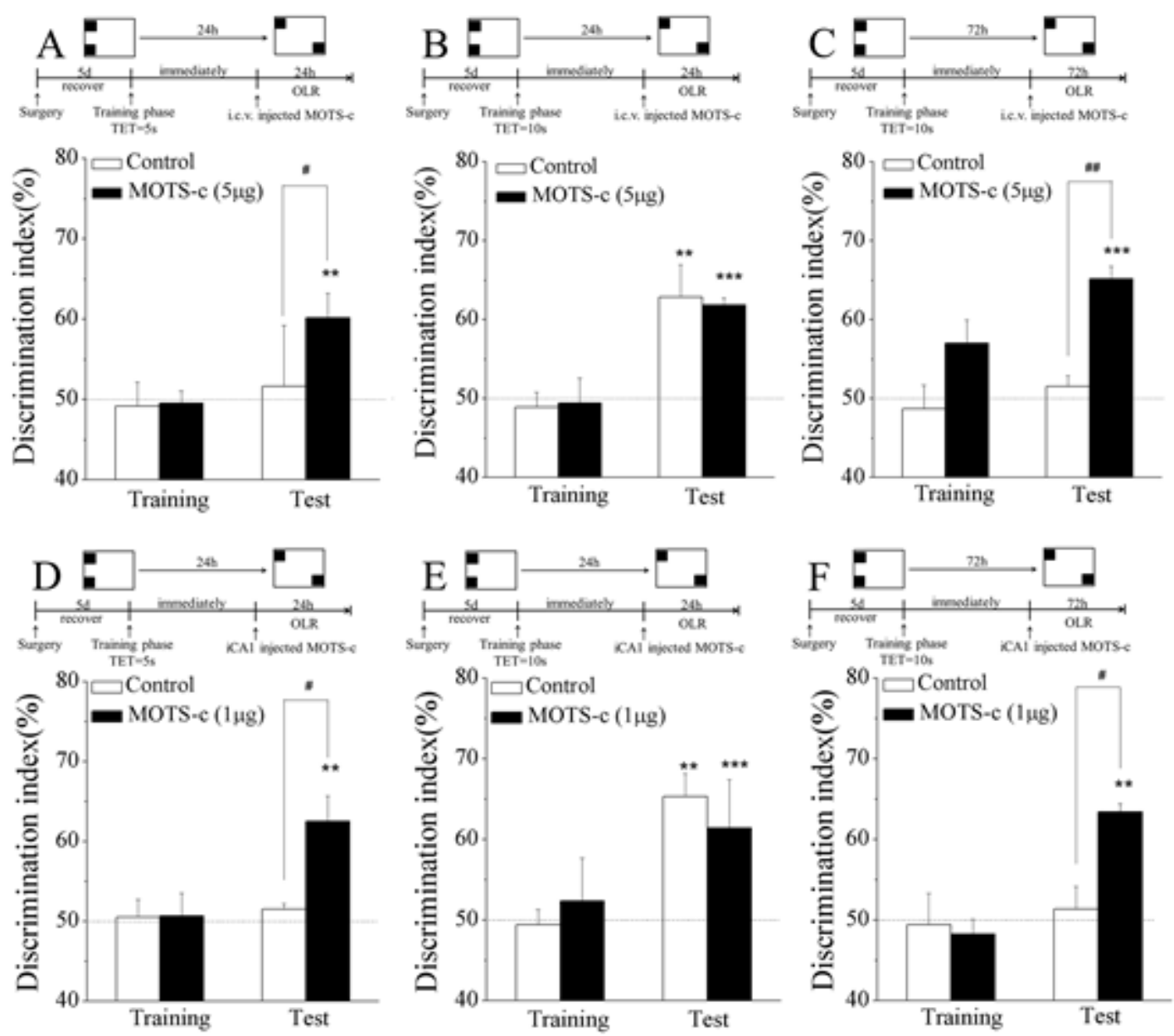

Figure 2

Central injection MOTS-c promotes the formation and consolidation of location recognition memory. In OLR task, when TET was $5 \mathrm{~s}$ and the mice were tested after $24 \mathrm{~h}$, i.c.v. injection (A) or intrahippocampal CA1 microinjection of MOTS-C (D) immediately after training showed a good object location recognition memory performance, whereas the control group had a poor memory rate, close to the $50 \%$ random level. ( $B$ and $E$ ) When TET was $10 \mathrm{~s}$, and the mice were tested after $24 \mathrm{~h}$, the control group and MOTS-c group (i.c.v. and iCA1) showed good object recognition memory. (C and F) When TET was $10 \mathrm{~s}$, and the mice were tested after $72 \mathrm{~h}$, the control group failed to distinguish between new location and familiar one, whereas MOTS-c group (i.c.v. and iCA1) showed good location recognition memory. One-way ANOVA analysis displayed that there was a significant difference compared with the control mice. The dashed line indicates $50 \%$ chance level. $n=6-10$ mice per group. Vertical lines represent mean \pm SEM. T-test: ** $<$ 0.01 and ${ }^{\star \star} p<0.001$ compared with $50 \%$ chance level. One-way ANOVA: \#p $<0.05$ and $\# \# p<0.01$ compared with control group. 


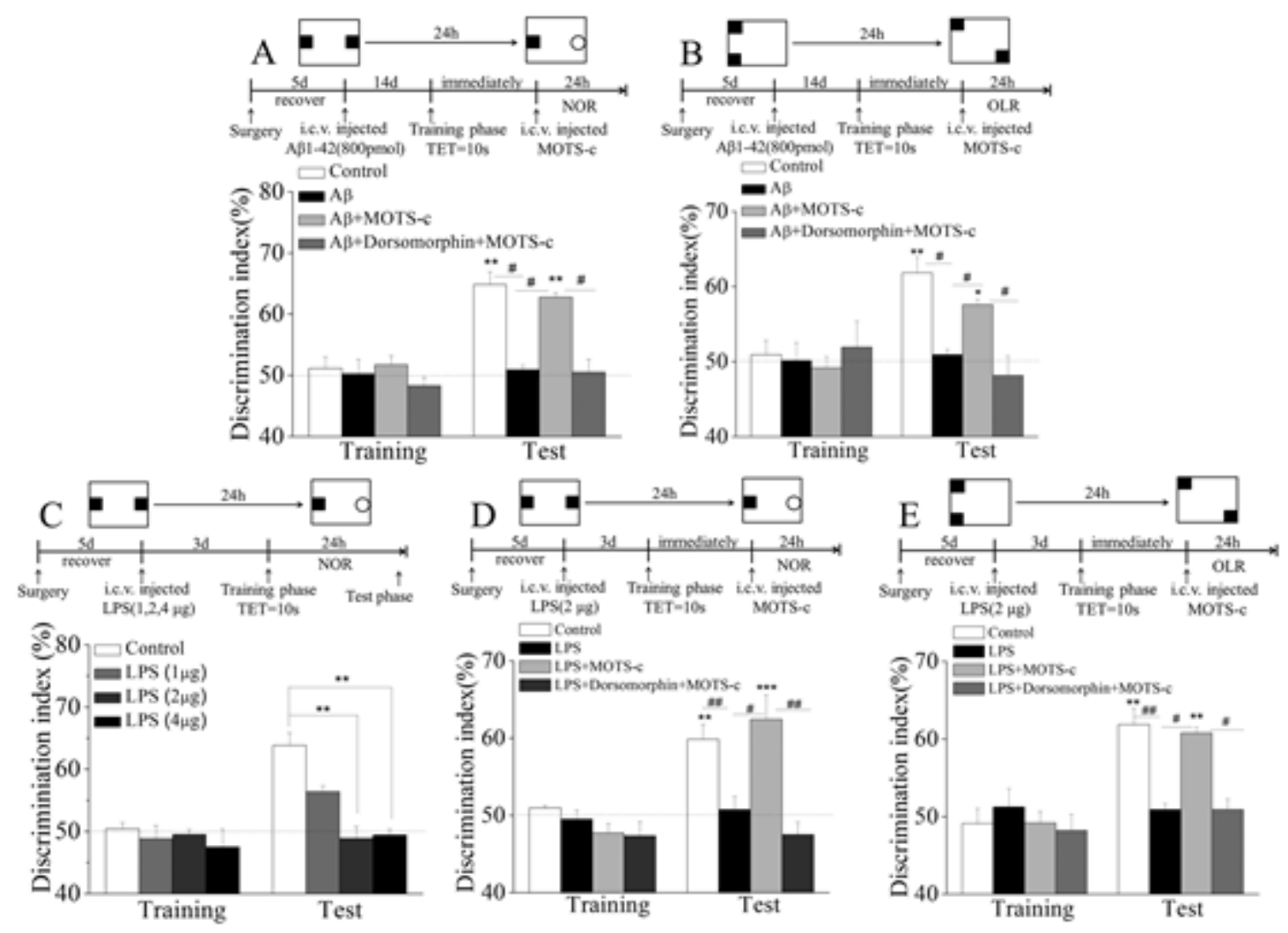

Figure 3

MOTS-c attenuates AB1-42 or LPS induced memory impairments in NOR and OLR tasks. (A-B) AB1-42 was administered by i.c.v. injection at $14 \mathrm{~d}$ prior to MOTS-c application, and it treatment significantly disrupted memory compared with control group. Injection of MOTS-c $(5 \mu \mathrm{g} / \mathrm{mouse}$, i.c.v.) immediately after training improves amnesia elicited by A $\beta 1-42$ ( $800 \mathrm{pmol} / \mathrm{mouse}$, i.c.v.) when TET was $10 \mathrm{~s}$ and mice were tested after $24 \mathrm{~h}$. The memory-improving effects of MOTS-c could be blocked by dorsomorphin, an inhibitor of the AMPK. (C) LPS (1, 2 and $4 \mu \mathrm{g}$ /mouse) were administered by i.c.v. injection at $3 \mathrm{~d}$ prior to MOTS-c application. (D-E) MOTS-c ( $5 \mu \mathrm{g} /$ mouse, i.c.v.) immediately after training improves LPS elicited object or location recognition memory impairments when TET was $10 \mathrm{~s}$ and mice were tested after $24 \mathrm{~h}$. Injection of dorsomorphin immediately after training blocked memory improvement induced by MOTS-c $(5 \mu \mathrm{g})$. The dashed line indicates $50 \%$ chance level. $n=7-11$ mice per group. Vertical lines represent mean \pm SEM. T-test: ${ }^{*} p<0.05,{ }^{\star *} p<0.01$ and ${ }^{\star \star \star} p<<0.001$ compared with $50 \%$ chance level. One-way ANOVA: $\# p<0.05$ and \#\#p $<0.01$ compared with Aß1-42 or LPS group. 

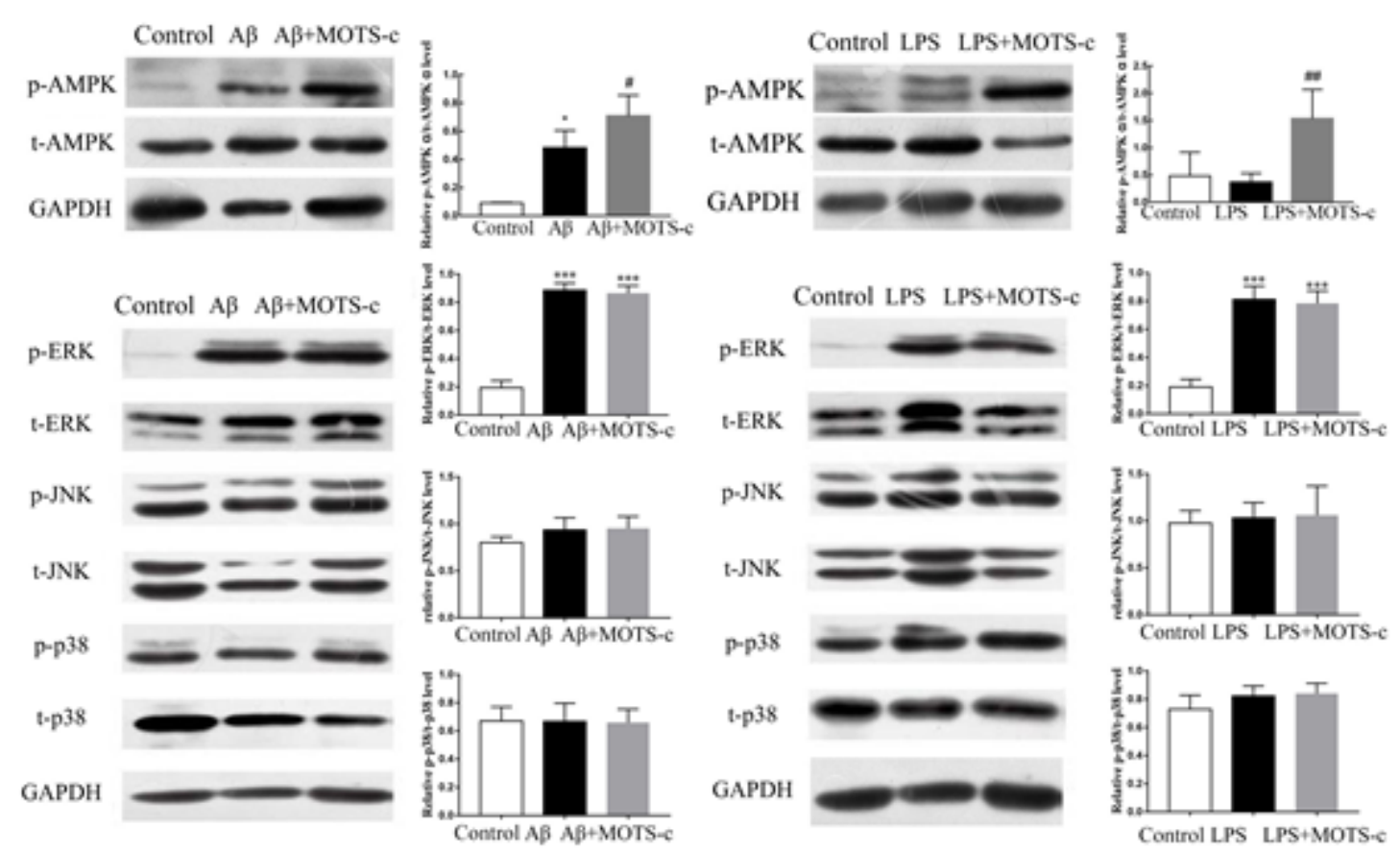

\section{Figure 4}

Effects of MOTS-c treatment on the expression of AMPK and MAPK signaling pathway in the hippocampus. (A-B) Left panel is western blot analysis of pAMPK, tAMPK and GAPDH in each group of hippocampus. Right panel is quantification of pAMPK expressed as the ratio of pAMPK/tAMPK. (C-D) Left panel representative immunoblot of pERK, tERK, pJNK, tJNK, p38, p-p38 and GAPDH detected in each group of hippocampus by western blotting. Right panel is quantification of MAPK signaling pathway related protein expressed as the ratio of $p E R K / t E R K, p J N K / t J N K$ and $p-p 38 / p 38$. Values were expressed as mean $\pm S E M, n=5$ in each group. ${ }^{*} p<0.05$ compared with control group, $\# p<0.05$ and $\# \# p<0.01$ compared with $A \beta 1-42$ or LPS group. 

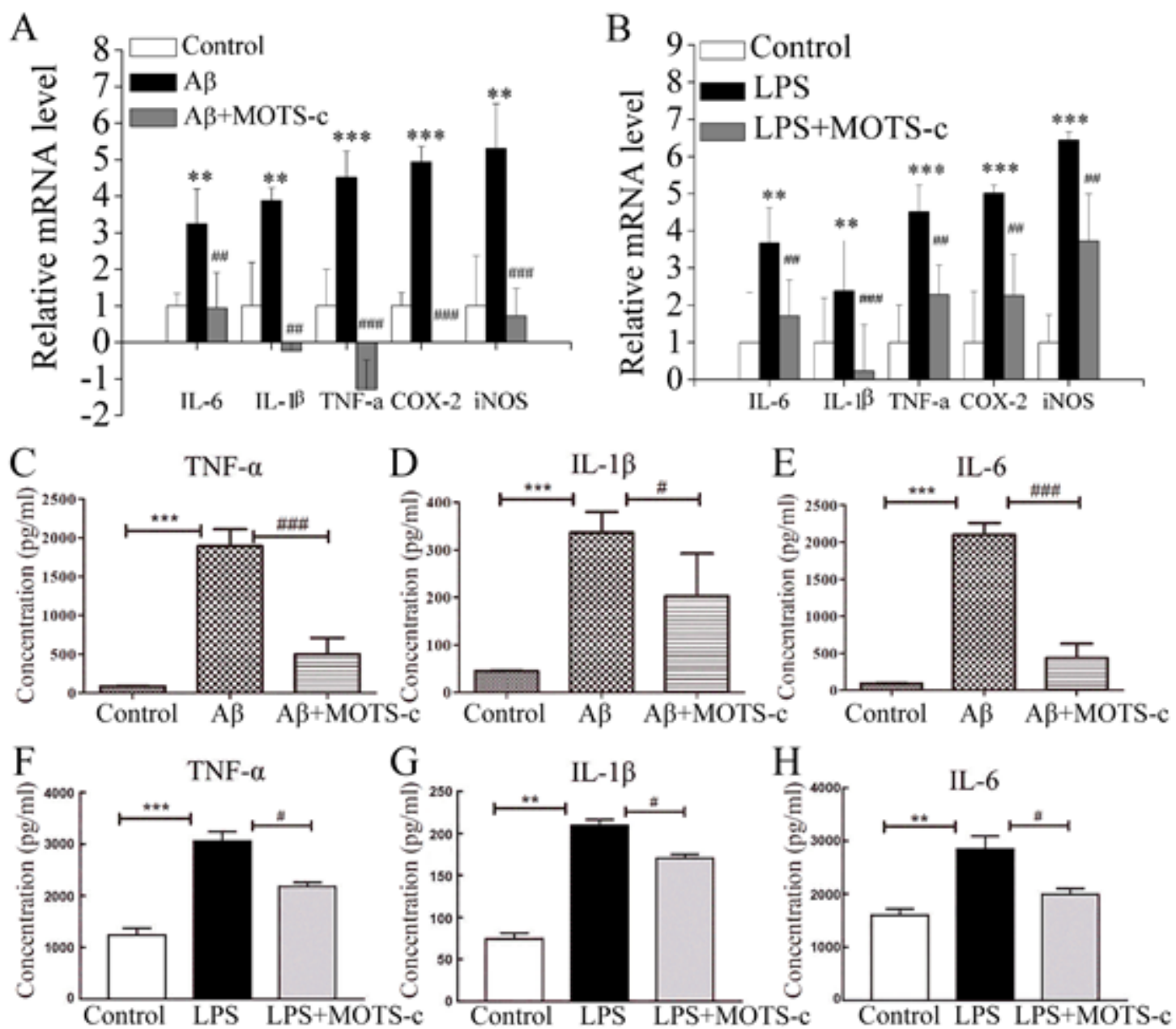

\section{Figure 5}

Effects of MOTS-c treatment on the expression of pro-inflammatory factors in the hippocampus. (A-B) The mRNA levels of pro-inflammatory cytokines, IL-6, IL-1 $\beta$, TNF- $a$, COX-2 and iNOS were determined by real-time PCR. Note that IL-6, IL-1 $\beta$, TNF-a, COX-2 and iNOS levels were significantly increased in the A 31 42 group ( $n=5$, respectively) or LPS group ( $n=5$ respectively) and this increase was counteracted by treatment with MOTS-c $(n=5$ respectively). $(\mathrm{C}-\mathrm{H})$ Hippocampal levels of pro-inflammatory cytokines, TNF$a$, IL-1 $\beta$ and IL- 6 were evaluated by elisa assay. Note TNF- $a$, IL-1 $\beta$ and IL- 6 levels showed significant increase in the A 1-42 group or LPS group and following MOTS-c treatment in the A 1-42+MOTS-c group or LPS+MOTS-c group were recovered to control levels. $n=5$ mice per group, respectively. Values were expressed as mean \pm SEM. ${ }^{\star \star} p<0.01$ and ${ }^{* \star \star} p<0.001$ compared with control group. $\# p<0.05$, \#\#p < 0.01 and \#\#\#p < 0.001 compared with $A \beta 1-42$ or LPS group. 


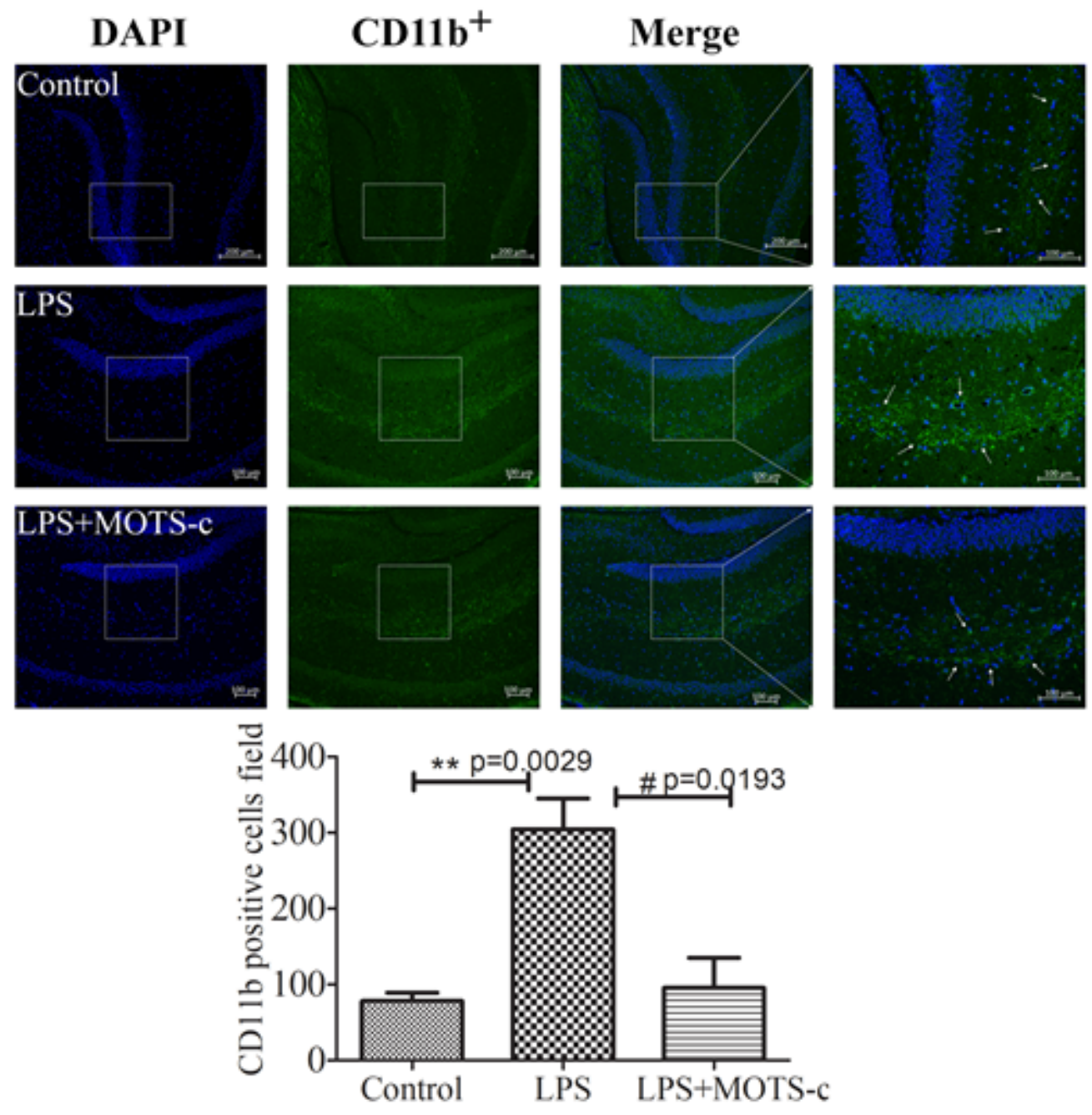

Figure 6

Effect of MOTS-c treatment in LPS-induced the activation of microglia. Representative confocal images of mice administered with saline, LPS or LPS+MOTS-c are shown. Hippocampal histology sections were double-labeled for CD11b+ (green) and DAPI (blue), assessments were made with immunofluorescence microscopy, scale bars $=100 \mu \mathrm{m}$. Lower panel is quantification of CD11b-positive microglia is described. Data are mean \pm SEM ( $n=5$ mice per group). Data were analyzed using one-way ANOVA followed by Bonferroni's post-hoc test. ${ }^{\star \star} p<0.01$ compared with control. $\# p<0.05$ compared with LPS group. 

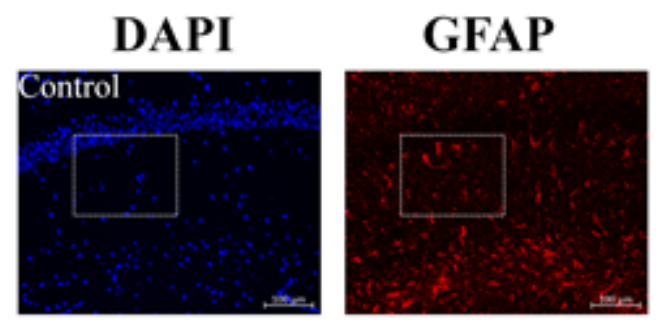

\section{Merge}
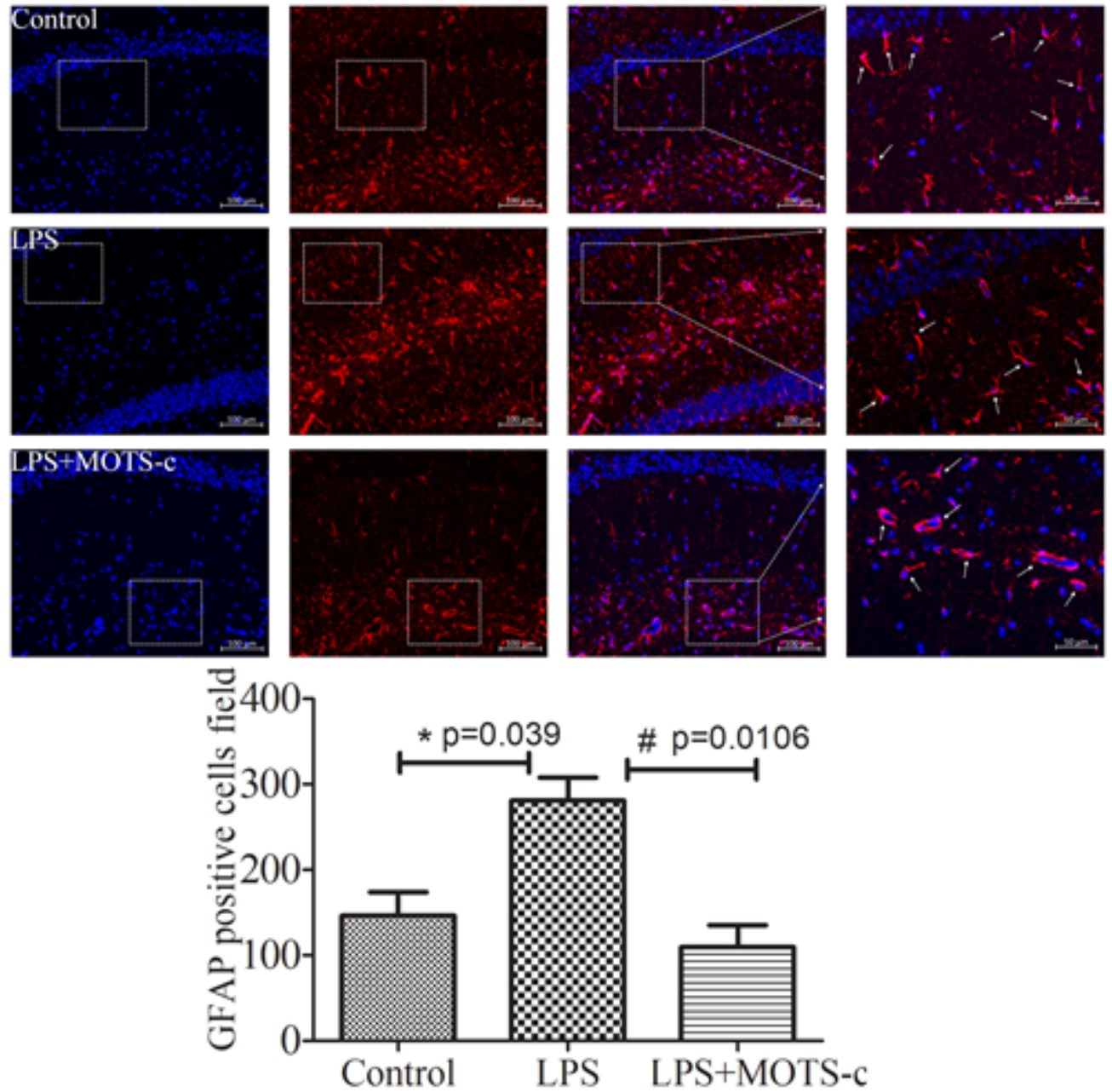

Figure 7

Effect of MOTS-c treatment in LPS-induced the activation of astrocytes. Hippocampal histology sections were double-labeled for GFAP (red) and DAPI (blue), assessments were made with immunofluorescence microscopy, scale bars $=100 \mu \mathrm{m}$. Lower panel is quantification of GFAP-positive astrocytes is described. Data are mean \pm SEM ( $n=5-6$ mice per group). Data were analyzed using one-way ANOVA followed by Bonferroni's post-hoc test. ${ }^{*} p<0.05$ compared with control. $\# p<0.05$ compared with LPS group.
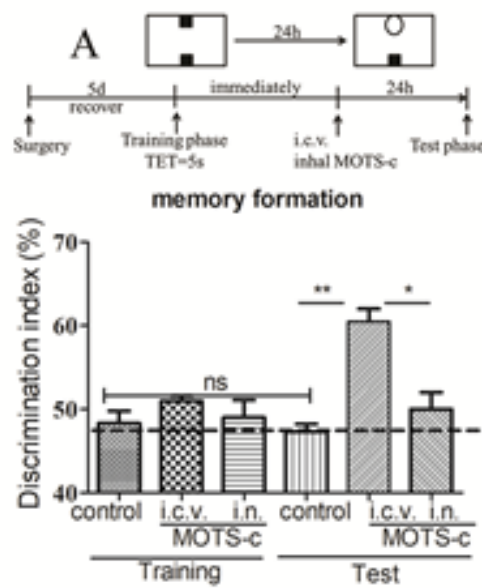
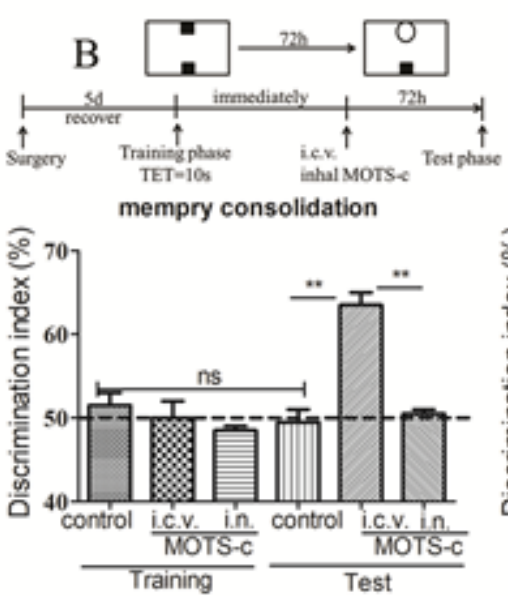

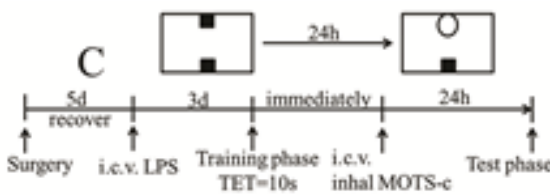

memory deficit

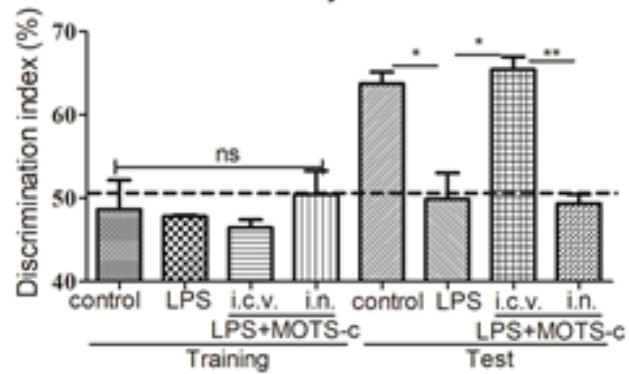




\section{Figure 8}

Evaluation of MOTS-c into BBB. (A-B) In NOR task, i.c.v. administration of MOTS-c $(5 \mu \mathrm{g})$ promoted the formation and consolidation of object recognition memory, while i.n. administration of MOTS-c (50 $\mu \mathrm{g} /$ mouse, i.n.) could not make a distinction between the novel object and the familiar one. (C) In the LPS-induced memory impairment model, i.c.v. injection of MOTS-c could improve LPS induced memory impairment, while MOTS-c (50 $\mu \mathrm{g} /$ mouse, i.n.) treatment still no effect. All data are expressed as mean \pm SEM and were analyzed by one-way ANOVA followed by Bonferroni's post-hoc test. $n=7-9$ mice per group.

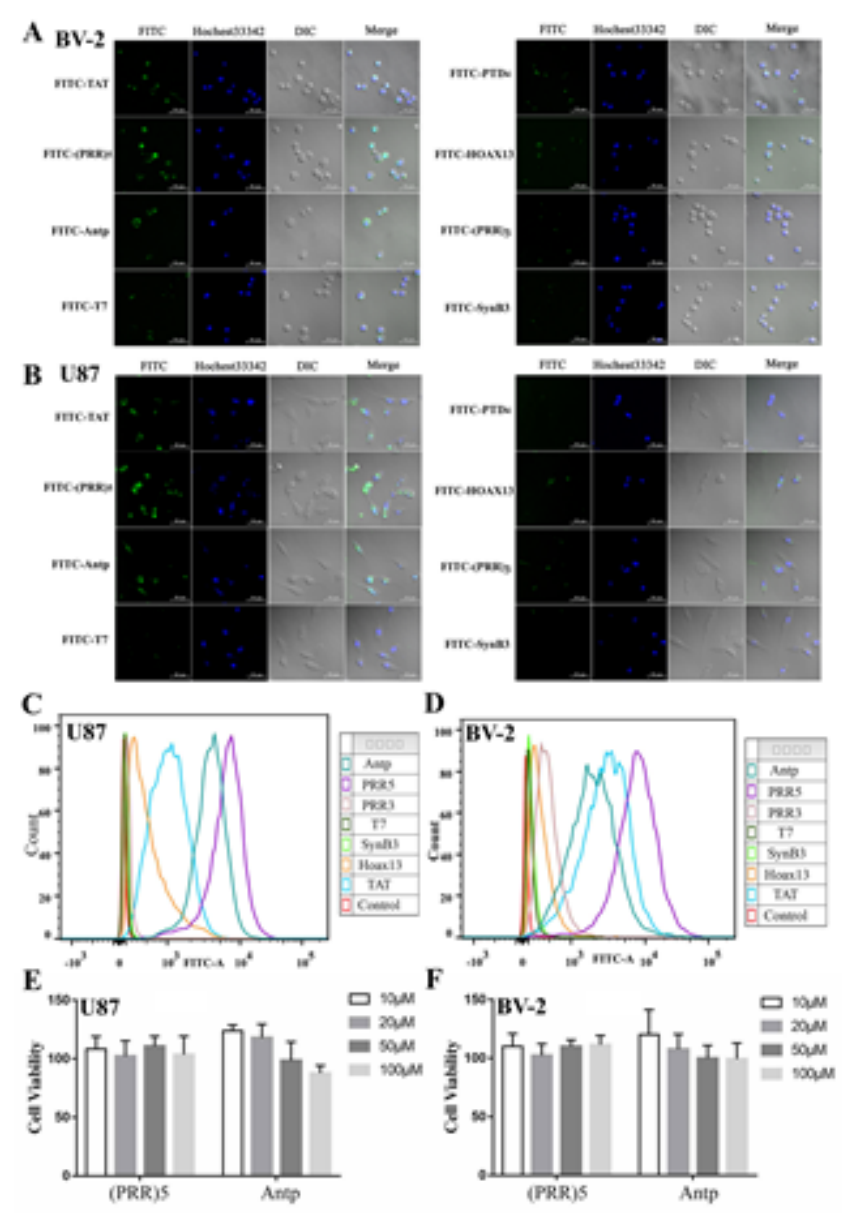

\section{Figure 9}

Screening of a series of brain-targeted cell penetrating peptides. (A-B) Confocal laser scanning microscopy experiments showed the transmembrane ability of a series of cell penetrating peptides on BV2 and $U 87$ cells, respectively (scale bar, $50 \mu \mathrm{m}$ ). (C-D) Flow cytometry experiments showed the transmembrane ability of a series of cell penetrating peptides on BV-2 and U87 cells, respectively. (E-F) MTT assays evaluated the cytotoxicity of (PRR) 5 and Antp at different doses on BV-2 and U87 cells. All data are expressed as mean \pm SEM. $n=4-5$ times. 

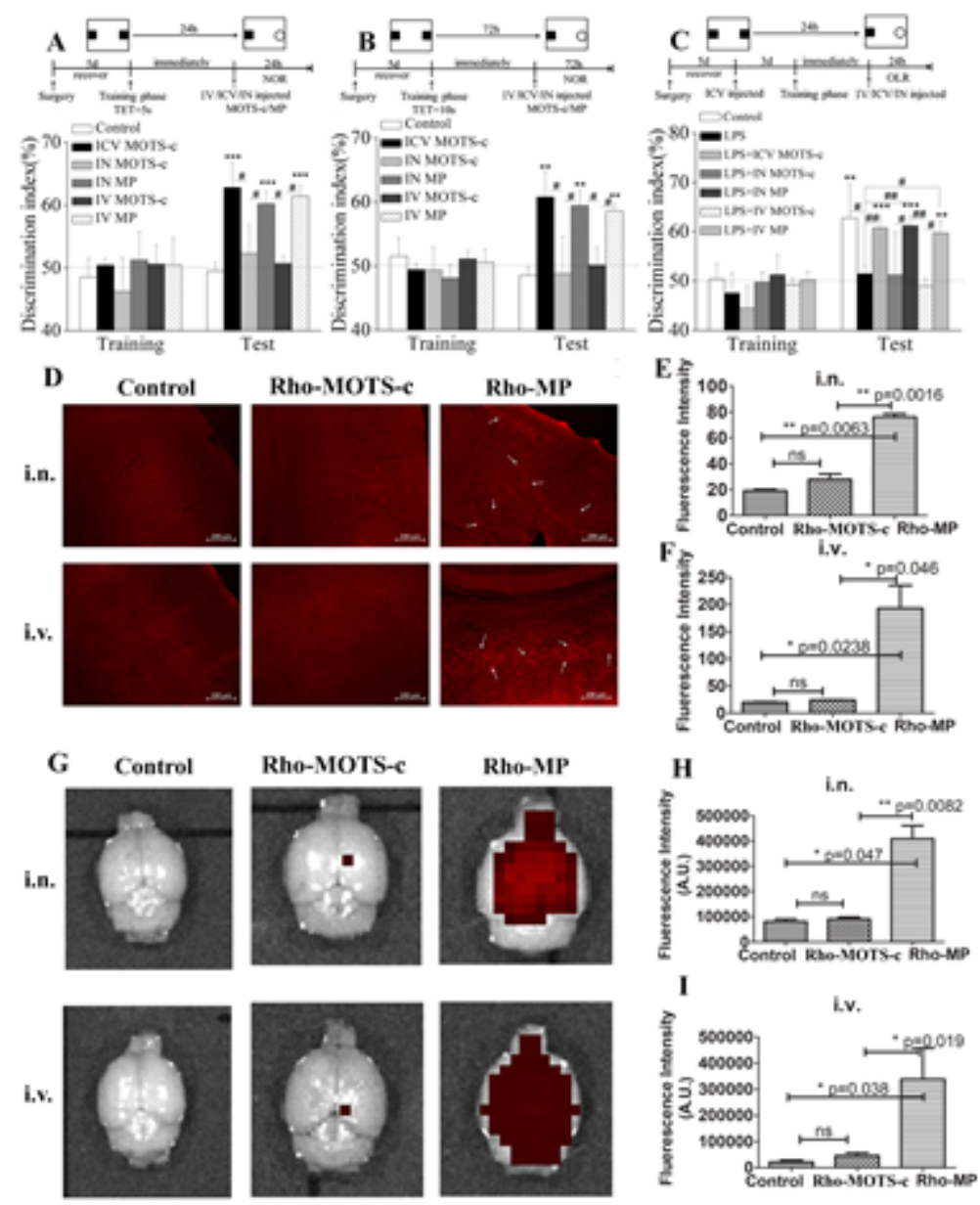

Figure 10

Pharmacological activity and central targeting of peripheral administration of MP. (A-B) In NOR task, i.c.v. administration of MOTS-c $(5 \mu \mathrm{g})$ promoted the formation and consolidation of object recognition memory, while i.n. administration of MOTS-c ( $50 \mu \mathrm{g} / \mathrm{mouse}$, i.n.) or i.v. administration of MOTS-c (50 $\mu \mathrm{g} /$ mouse, i.v.) could not make a distinction between the novel object and the familiar one. Mice instilled with MP (50 $\mu \mathrm{g}$ for i.n. or i.v.) showed a good memory performance. (C) In the LPS-induced memory impairment model, i.c.v. injection of MOTS-c could improve LPS induced memory impairment, while MOTS-c (50 $\mu \mathrm{g} / \mathrm{mouse}$ i.n. or i.v.) treatment still no effect. MP application $(50 \mu \mathrm{g} / \mathrm{mouse}$, i.n. or i.v.) significantly alleviated the object recognition memory-impairing effects of LPS. (D-F) After i.n. or i.v. administration of saline, Rho-MOTS-c and Rho-MP $2 \mathrm{~h}$, confocal microscopy images showed that RhoMP was widely distributed in brain regions of mice, whereas saline and Rho-MOTS-c groups have fewer fluorescence distributions. (G-I) Ex vivo NIR fluorescence imaging and fluorescence intensity of perfused mouse brains $2 \mathrm{~h}$ after i.n. or i.v. injection of saline, Rho-MOTS-c and Rho-MP, saline and Rho-MOTS-c as controls. Compared with control and Rho-MOTS-c groups, significant fluorescence signals of Rho-MP were detected in the brain by NIR fluorescence imaging. All data are expressed as mean \pm SEM and were analyzed by one-way ANOVA followed by Bonferroni's post-hoc test. $n=6-9$ mice per group.

\section{Supplementary Files}


This is a list of supplementary files associated with this preprint. Click to download.

- Supplementarymaterial.docx 